Check for updates

Cite this: RSC Adv., 2018, 8, 7494

Received 25th November 2017 Accepted 10th February 2018

DOI: $10.1039 / c 7 r a 12768 e$

rsc.li/rsc-advances

\section{Sulfonated graphene oxide/Nafion composite membranes for high temperature and low humidity proton exchange membrane fuel cells $\dagger$}

\author{
Mohanraj Vinothkannan, ${ }^{a}$ Ae Rhan Kim, ${ }^{* b}$ G. Gnana kumar (D) ${ }^{c}$ and Dong Jin Yoo (DD *ad
}

Iron oxide $\left(\mathrm{Fe}_{3} \mathrm{O}_{4}\right)$ nanoparticles anchored over sulfonated graphene oxide (SGO) and $\mathrm{Nafion} / \mathrm{Fe}_{3} \mathrm{O}_{4}-\mathrm{SGO}$ composites were fabricated and applied as potential proton exchange membranes in proton exchange membrane fuel cells (PEMFCs) operated at high temperature and low humidity. $\mathrm{Fe}_{3} \mathrm{O}_{4}$ nanoparticles bridge SGO and Nafion through electrostatic interaction/hydrogen bonding and increased the intrinsic thermal and mechanical stabilities of $\mathrm{Nafion} / \mathrm{Fe}_{3} \mathrm{O}_{4}-\mathrm{SGO}$ composite membranes. Nafion $/ \mathrm{Fe}_{3} \mathrm{O}_{4}-\mathrm{SGO}$ composite membranes increased the compactness of ionic domains and enhanced the water absorption and proton conductivity while restricting hydrogen permeability across the membranes. The proton conductivity of Nafion/ $\mathrm{Fe}_{3} \mathrm{O}_{4}-\mathrm{SGO}$ (3 wt\%) composite membrane at $120{ }^{\circ} \mathrm{C}$ under $20 \%$ relative humidity $(\mathrm{RH})$ was $11.62 \mathrm{mS} \mathrm{cm} \mathrm{cm}^{-1}$, which is 4.74 fold higher than that of a pristine recast Nafion membrane. PEMFC containing the Nafion/ $/ \mathrm{Fe}_{3} \mathrm{O}_{4}-\mathrm{SGO}$ composite membrane delivered a peak power density of $258.82 \mathrm{~mW} \mathrm{~cm}{ }^{-2}$ at a load current density of $640.73 \mathrm{~mA} \mathrm{~cm} \mathrm{~cm}^{-2}$ while operating at $120{ }^{\circ} \mathrm{C}$ under 25\% RH and ambient pressure. In contrast, under identical operating conditions, a peak power density of only $144.89 \mathrm{~mW} \mathrm{~cm} \mathrm{~cm}^{-2}$ was achieved with the pristine recast Nafion membrane at a load current density of $431.36 \mathrm{~mA} \mathrm{~cm}{ }^{-2}$. Thus, Nafion/ $/ \mathrm{Fe}_{3} \mathrm{O}_{4}-\mathrm{SGO}$ composite membranes can be used to address various critical problems associated with commercial Nafion membranes in PEMFC applications.

\section{Introduction}

Proton exchange membrane fuel cells (PEMFCs) operating at high temperature and low humidity are considered as advanced electrochemical energy conversion systems owing to their advantages of fast electrode reaction kinetics, limited requirement for a precious metal (Pt) catalyst, improved electrocatalytic CO tolerance and simplified water and thermal management. ${ }^{\mathbf{1} 4}$ One method to realize the practical application of such PEMFCs is to employ a proton exchange membrane (PEM) that is able to operate under high temperature and low humidity conditions. Until now, perflurorosulfonic acid (PFSA) membranes such as Nafion are considered state-of-the-art PEMs, which have long term durability, high electronic insulation, high proton

${ }^{a}$ Graduate School, Department of Energy Storage/Conversion Engineering, Hydrogen and Fuel Cell Research Center, Chonbuk National University, Jeollabuk-do 54896, Republic of Korea

${ }^{b}$ Department of Bioenvironmental Chemistry, R\&D Center for CANUTECH, Business Incubation Center, Chonbuk National University, Jeollabuk-do 54896, Republic of Korea.E-mail: canutech@hanmail.net

${ }^{c}$ Department of Physical Chemistry, School of Chemistry, Madurai Kamaraj University, Madurai 625021, Tamil Nadu, India

${ }^{d}$ Department of Life Science, Chonbuk National University, Jeollabuk-do 54896, Republic of Korea. E-mail: djyoo@jbnu.ac.kr

$\uparrow$ Electronic supplementary information (ESI) available. See DOI: $10.1039 / \mathrm{c} 7 \mathrm{ra} 12768 \mathrm{e}$ conductivity and unique hydrophilic percolation; ${ }^{5-8}$ unfortunately, the water uptake and consequently the proton conductivity of a Nafion membrane decrease by orders of magnitude during PEMFC operation at high temperature $\left(>80^{\circ} \mathrm{C}\right)$ and low humidity $(<50 \%)$, owing to its inability to retain water in ionic clusters. ${ }^{1,9}$ Besides, Nafion membrane exhibits high hydrogen permeability denoted to as high hydrogen crossover from the anode to cathode through PEM as a result of concentration gradient. ${ }^{10,11}$ Accordingly, researchers are developing modified PFSA membranes or designing alternative PEMs. Incorporation of inorganic fillers, such as $\mathrm{SiO}_{2}, \mathrm{ZrO}_{2}, \mathrm{CeO}_{2}, \mathrm{ZnO}_{2}, \mathrm{TiO}_{2}$ and zeolite nanoparticles and $\mathrm{ZrO}_{2}, \mathrm{CeO}_{2}$ and $\mathrm{TiO}_{2}$ nanotubes, into the Nafion matrix has been demonstrated to result in composite PEMs with promising water uptake and consequently proton conductivity at high temperature and low humidity.,12-16 Although the addition of inorganic fillers into Nafion matrix led to reorganized ion conducting channels (consisting of pendent sulfonic acid groups and embedded hydrophilic inorganic fillers), inorganic fillers without any sulfonic acid group often reduces the proton conductivity at hydrated condition, owing to a decrease in net volume of sulfonic acid contents in composite PEMs. ${ }^{17}$

Carbon nanomaterials with sulfonic acid groups have drawn attention in fabrication of composites with Nafion as they can increase the proton conductivity by increasing number of sulfonate groups per cluster volume of each domain and extend 
the mechanical strength by reorganizing aliphatic backbone chains. Rambabu et al. ${ }^{18}$ embedded sulfonic acid functionalized fullerene (FF) into a Nafion matrix to prepare a composite membrane. They reported that at $1 \mathrm{wt} \% \mathrm{FF}$ loading, composite membrane shows an increase in tensile strength by 1.13 fold and in proton conductivity by 1.24 fold with respect to pristine Nafion membrane. Liu et al. ${ }^{19}$ incorporated multiwalled carbon nanotubes (MWCNTs) that were functionalized with Nafion into a Nafion matrix to prepare a composite membrane. In this work, the mechanical strength and proton conductivity of composite membrane were found to be increased up to a reasonable margin upon incorporating 0.05 wt\% Nafion-MWCNTs. These results were attributed to high compatibility between NafionMWCNTs and Nafion matrix because Nafion chains on the surface of MWCNTs connect with hydrophilic domains of Nafion matrix and facilitate the dispersion.

Graphene is a single atom thick two-dimensional layer of $\mathrm{sp}^{2}$-hybridized carbon discovered by Geim et al., ${ }^{20}$ and is associated with exceptional extended surface, unique $\pi$-bond delocalized hexagonal structure, excellent thermomechanical stability and high young's modulus that are beneficial to its wide use in the fields of sensors, ${ }^{21}$ catalysis, ${ }^{22}$ adsorption, ${ }^{23}$ nanoelectronics ${ }^{24}$ and energy conversion and storage. ${ }^{25-27}$ For the integration of graphene into PEM, it is essential to functionalize/oxidize $\mathrm{sp}^{2}$-hybridized carbon networks to convert the material as a protonic conductor and electronic insulator. ${ }^{28}$ The oxygen-related functional groups (e.g. $-\mathrm{OH},-\mathrm{O}-$ and $-\mathrm{CO}_{2} \mathrm{H}$ ) over $\mathrm{GO}$ were reported to exhibit a conductivity of $\sim 0.001 \mathrm{~S} \mathrm{~cm}^{-1}$ at $300 \mathrm{~K}^{29}$ However, substituting $-\mathrm{OH},-\mathrm{O}-$ and $-\mathrm{CO}_{2} \mathrm{H}$ groups of $\mathrm{GO}$ with sulfonic acid containing organic moiety enhances the proton conductivity by many fold owing to a prompt proton conducting behavior of sulfonic acid group. Furthermore, the interfacial hydrogen bonds formed between different kinds of oxygen-related functional groups of sulfonated GO (SGO) and polymer aid in the construction of extended architecture of proton conducting channels, which further facilitate the diffusion of protons. ${ }^{2}$ Several PEMs were explored with SGO based fillers. As example, Zarrin et al. ${ }^{1}$ prepared SGO/Nafion composite membrane and demonstrated it to PEMFC operating under high temperature and low humidity. The GO was produced from natural graphite flakes by modified Hummers method and then functionalized using 3mercaptopropyl trimethoxysilane as sulfonic acid group precursor. They found that maximum power density of SGO/ Nafion membrane increases by 3.98 fold over pristine Nafion membrane at $120{ }^{\circ} \mathrm{C}$ and $25 \% \mathrm{RH}$. Shau et al. ${ }^{17}$ fabricated the sulfonic acid functionalized graphene (S-graphene)/Nafion composite membrane and applied it in low humidity PEMFC. The functionalization of graphene was performed by sulfonic acid containing aryl radicals to increase the number of sulfonate groups per cluster volume of graphene domain. It was found that peak power density of S-graphene/Nafion membrane increases by 1.36 fold compared to that of pristine Nafion membrane at $70{ }^{\circ} \mathrm{C}$ and $20 \%$ RH. Beydaghi et al. ${ }^{30}$ prepared PVA composite membrane that was prepared using SGO and PVA solution. It was found that tensile strength and proton conductivity of SGO/PVA membrane are higher with respect to pristine PVA membrane. The higher tensile strength was due to effectual stress transfer to SGO sheets through interfacial hydrogen bonds. The higher proton conductivity was attributed to chemical interactions between different kinds of oxygencontaining functional groups of SGO and PVA. Although SGO based PEMs are reported by several research groups, the realization of a complete physiochemical, thermomechanical, electrochemical and fuel barrier properties have rarely been investigated.

On the other side, incorporation of metal oxide nanoparticles-anchored SGO sheets into PEM is an ultimate strategy in improving the dispersion of SGO sheets, which facilitates the surface roughness of PEM and compatibility with electrodes. Among the studied metal oxide nanoparticles, $\mathrm{Fe}_{3} \mathrm{O}_{4}$ has synthesis flexibility and eco friendliness and is the efficient catalyst for various electrochemical reactions. ${ }^{31,32} \quad \mathrm{Fe}_{3} \mathrm{O}_{4}$ possesses a high density of - $\mathrm{OH}$ groups that generate hydrogen bonds with free water existing in membrane thereby slow down the evaporation of water from membrane and facilitate the proton transfer by vehicle mechanism. ${ }^{33}$ Besides, the interfacial hydrogen bonding between - $\mathrm{OH}$ groups of $\mathrm{Fe}_{3} \mathrm{O}_{4}$ and sulfonic acid $\left(-\mathrm{SO}_{3} \mathrm{H}\right)$ groups and fluorine atoms $(-\mathrm{F})$ of Nafion enhances thermal and mechanical stabilities of the composite membrane. ${ }^{9}$ If the $\mathrm{Fe}_{3} \mathrm{O}_{4}$ anchored SGO sheets could be effectually intercalated into the Nafion matrix, superior properties with respect to pristine Nafion could be capitalized, which may bring out ameliorated PEMFC performance. Again the existence of $\mathrm{Fe}_{3} \mathrm{O}_{4}$ into the polymer matrix is a problem that facilitates the oxidative degradation of PEM when combined with hydroxyl $\left(\mathrm{OH}^{*}\right)$ and hydroperoxyl $\left(\mathrm{OOH}^{*}\right)$ radicals formed in cathode during PEMFC operation. Recently, Beydaghi et al. ${ }^{9}$ reported that the addition of 5 wt $\% \mathrm{Fe}_{3} \mathrm{O}_{4}$-SGO could increase the durability of SPEEK/PVA blend significantly. During $120 \mathrm{~h}$ of operation, the fuel cell equipped with $\mathrm{Fe}_{3} \mathrm{O}_{4}-\mathrm{SGO} / \mathrm{SPEEK} / \mathrm{PVA}$ membrane showed a OCV reduction of $0.65 \mathrm{mV} \mathrm{h}^{-1}$, which is lower by a factor of 1.3 compared to that of fuel cell equipped with SPEEK/PVA membrane $\left(0.85 \mathrm{mV} \mathrm{h}^{-1}\right)$. Thus, addition of $\mathrm{Fe}_{3} \mathrm{O}_{4}$ with SGO is a better approach to suppress the effect of oxidative degradation on $\mathrm{PEM}$, because $\mathrm{Fe}_{3} \mathrm{O}_{4}$ intercalates between the SGO layers which precludes the direct exposure of $\mathrm{Fe}_{3} \mathrm{O}_{4}$ to $\mathrm{OH}^{*}$ and $\mathrm{OOH}^{*}$ radicals. The intention of the present study is to investigate the impact of a combination of composite filler $\left(\mathrm{Fe}_{3} \mathrm{O}_{4}-\mathrm{SGO}\right)$ and Nafion on performance of PEMFC operating under high temperature and low humidity through its morphological, thermomechanical, electrochemical and fuel barrier properties.

\section{Experimental section}

\subsection{Materials}

Natural graphite powder, iron(III) chloride hexahydrate $\left(\mathrm{FeCl}_{3}\right.$ $\left.\cdot 6 \mathrm{H}_{2} \mathrm{O}, 97 \%\right)$, iron(II) sulphate heptahydrate $\left(\mathrm{FeSO}_{4} \cdot 7 \mathrm{H}_{2} \mathrm{O}\right.$, $99 \%)$, sodium nitrate $\left(\mathrm{NaNO}_{3}, 99 \%\right)$, sodium nitrite $\left(\mathrm{NaNO}_{2}\right.$, 97\%), sodium borohydride $\left(\mathrm{NaBH}_{4}, 98 \%\right)$ and potassium permanganate $\left(\mathrm{KMnO}_{4}, 99.3 \%\right)$ were received from Alfa Aesar. Sulfanilic acid $\left(\mathrm{C}_{6} \mathrm{H}_{7} \mathrm{NO}_{3} \mathrm{~S}, 99 \%\right)$, sulfuric acid $\left(\mathrm{H}_{2} \mathrm{SO}_{4}, 95 \%\right)$, hydrogen peroxide $\left(\mathrm{H}_{2} \mathrm{O}_{2}, 32 \%\right)$ and hydrochloric acid $(\mathrm{HCl}$, 
$35 \%)$ were procured from Daejung Chemicals, South Korea. Nafion solution (5\%) in lower aliphatic alcohols and ammonium hydroxide $\left(\mathrm{NH}_{3} \mathrm{OH}, 5 \mathrm{M}\right)$ were procured from Sigma Aldrich. $N, N$-Dimethylformamide (DMF) was obtained from Duksan reagents, South Korea. Gas diffusion electrodes (40 wt $\%$ Pt on XC-72) were procured form NARA Cell Tech, South Korea.

\subsection{Synthesis of phenyl sulfonated $\mathrm{GO}$ and $\mathrm{Fe}_{3} \mathrm{O}_{4}-\mathrm{SGO}$ composite}

First, GO was synthesized from natural graphite powder according to modified Hummers method as described in ref. 34 . SGO was then synthesized via a two-step process, similar to a procedure reported in ref. 30. In the first step, partial reduction of GO was performed by $\mathrm{NaBH}_{4}$. A $75 \mathrm{mg}$ of $\mathrm{GO}$ was dispersed in $75 \mathrm{~mL}$ of deionized (DI) water by ultrasonication for $1 \mathrm{~h}$. Then, $15 \mathrm{~mL}$ of $0.1 \mathrm{M} \mathrm{NaBH}_{4}$ was added dropwise into the GO dispersion and stirred at $80{ }^{\circ} \mathrm{C}$ for $1 \mathrm{~h}$. The reduced product was collected via centrifugation, washed several times with DI water and dried in oven at $100{ }^{\circ} \mathrm{C}$ for $12 \mathrm{~h}$. In the second step, aryl diazonium salt of sulfonic acid was grafted on reduced GO via diazonium coupling. A $75 \mathrm{mg}$ of reduced GO was dispersed in $75 \mathrm{~mL}$ of DI water by ultrasonication for $1 \mathrm{~h}$. Separately, $50 \mathrm{mg}$ of sulfanilic acid and $20 \mathrm{mg}$ of $\mathrm{NaNO}_{2}$ were dispersed in $1 \mathrm{M} \mathrm{HCl}$ solution by ultrasonication at $0-3{ }^{\circ} \mathrm{C}$. The obtained aryl diazonium salt of sulfonic acid was added into the dispersion of reduced GO with continuous stirring at $0-3{ }^{\circ} \mathrm{C}$. Subsequently, $5 \mathrm{~mL}$ of $80 \% \mathrm{~N}_{2} \mathrm{H}_{2}$ was added dropwise and stirred for another $3 \mathrm{~h}$. The resultant product was collected via centrifugation, washed several times with DI water and dried in oven at $100{ }^{\circ} \mathrm{C}$ for $12 \mathrm{~h}$.

$\mathrm{Fe}_{3} \mathrm{O}_{4}$-SGO composite was prepared via hydrothermal method. A $100 \mathrm{mg}$ of SGO was dispersed in $100 \mathrm{~mL}$ of DI water by ultrasonication for $1 \mathrm{~h}$. Separately, desired amount of $\mathrm{Fe}_{3} \mathrm{O}_{4}$ nanoparticles (produced by co-precipitation method, similar to a procedure reported in ref. 33) was dispersed in DI water and subsequently added into the SGO suspension. The resultant mixture was further sonicated for $1 \mathrm{~h}$, loaded into the Teflon lined stain less steel autoclave and heated at $180{ }^{\circ} \mathrm{C}$ for $12 \mathrm{~h}$. Afterward, the solid product was collected via centrifugation, washed several times with DI water and dried in oven at $100{ }^{\circ} \mathrm{C}$ for $12 \mathrm{~h}$.

\subsection{Preparation of composite membranes}

Nafion composite membranes were prepared via solution casting method. A $500 \mathrm{mg}$ of Nafion (precast membrane at $100{ }^{\circ} \mathrm{C}$ for $12 \mathrm{~h}$ ) was dissolved in $10 \mathrm{~mL}$ of DMF. Subsequently, the desired amount of $\mathrm{Fe}_{3} \mathrm{O}_{4}$-SGO (to achieve the weight ratios of $0.5,1.5$ or $3 \%$ ) was impregnated with the above solution to realize a composite membrane. The resultant mixture was sonicated for $1 \mathrm{~h}$ followed by mechanical stirring for $12 \mathrm{~h}$. Composite solution was poured on a clean Petri plate and allowed to dry under vacuum at $80{ }^{\circ} \mathrm{C}$ for $12 \mathrm{~h}$. Composite membrane thus formed was peeled off from Petri plate and dried at $120{ }^{\circ} \mathrm{C}$ for $2 \mathrm{~h}$ to remove solvent residues. Nafion (without filler) and GO composite membranes were also prepared to systematically compare their properties with respect to $\mathrm{Fe}_{3} \mathrm{O}_{4}-\mathrm{SGO}$ membrane. The prepared composite membranes such as Nafion/GO (3 wt\%), Nafion/ $\mathrm{Fe}_{3} \mathrm{O}_{4}-\mathrm{SGO}$ (0.5 wt\%), Nafion/ $\mathrm{Fe}_{3} \mathrm{O}_{4}-\mathrm{SGO}$ (1.5 wt $\%$ ) and $\mathrm{Nafion} / \mathrm{Fe}_{3} \mathrm{O}_{4}-\mathrm{SGO}$ (3 wt $\%$ ) has been designated as Nafion/GO-3, Nafion/SGF-0.5, Nafion/SGF-1.5 and Nafion/SGF-3, respectively. The thicknesses of the dry membranes were measured at three random points over the surface using a digital micrometer and were in the range from 50 to $80 \mu \mathrm{m}$. Although a high variation observed in thicknesses of dry membranes, the amount of Nafion was controlled in each membrane to be same and this ensures appropriate comparison between various samples. Finally, the membranes were pretreated by boiling in $3 \% \mathrm{H}_{2} \mathrm{O}_{2}, 1 \mathrm{M} \mathrm{H}_{2} \mathrm{SO}_{4}$ and $\mathrm{H}_{2} \mathrm{O}$ in sequence each for $1 \mathrm{~h}$. Scheme 1 illustrates the preparation process of Nafion/ $\mathrm{Fe}_{3} \mathrm{O}_{4}-\mathrm{SGO}$ composite membrane.

\section{Characterizations}

Surface morphology of GO, SGO and $\mathrm{Fe}_{3} \mathrm{O}_{4}$-SGO specimens was observed by transmission electron microscope (TEM) (JEM2010, JEOL) and field emission scanning electron microscope (FE-SEM) (SUPRA 40VP, ZEISS). Crystalline facets, surface defects, functional groups and thermal stability of GO, SGO and $\mathrm{Fe}_{3} \mathrm{O}_{4}$-SGO specimens were investigated by X-ray diffractometer (XRD) (X' pert-MRD equipped with CuK $\alpha$ radiation, Pro Philips), Raman spectrometer (HORIBA-Lab RAM-HR equipped with $\mathrm{He}-$ Ne laser beam), Fourier transform infrared spectroscopy (FT-IR) (GX spectrometer equipped with a DTGS detector, PerkinElmer) and thermogravimetric analyzer (TGA) (Q50-TA instruments) respectively. Surface and cross-sectional morphologies of pristine Nafion and composite membranes were observed by using a scanning electron microscope (SEM) (JSM-6400, JEOL). Crosssectional morphology and corresponding quantitative elemental mappings of composite membrane were performed by energy dispersive X-ray (EDX) spectroscopy coupled with SEM. Topographical difference on pristine Nafion and composite membranes was observed by atomic force microscope (AFM) (multimode-8 model, Bruker). The imaging was performed in contact mode using an ultra-sharp antimony doped silicon tip with a radius of around $20 \mathrm{~nm}$ and spring constant of around $40 \mathrm{~N} \mathrm{~m}^{-1}$. Line profiles were used to investigate the height variation at a particular cross-section on membrane surface. The deviation of actual membrane surface $[(x, y)]$ from an ideal atomically smooth surface $(\mu)$ is defined as surface roughness. The surface morphology of the membrane varies from area to area due to the variation in local surface roughness and crumpled surface. The root-mean-square (RMS) roughness $\left(S_{\mathrm{q}}\right)$ may give useful information about the surface topography of membrane, and it was calculated using the eqn (1):

$$
S_{\mathrm{q}}=\sqrt{\frac{1}{M N}} \sum_{K \rightarrow 0}^{M-1} \sum_{l \rightarrow 0}^{N-1}\left[Z\left(x_{k}-y_{l}\right)-\mu\right]
$$

where $M$ and $N$ are respective $x$ and $y$ points in the specimen area, $Z(x, y)$ is the surface and 


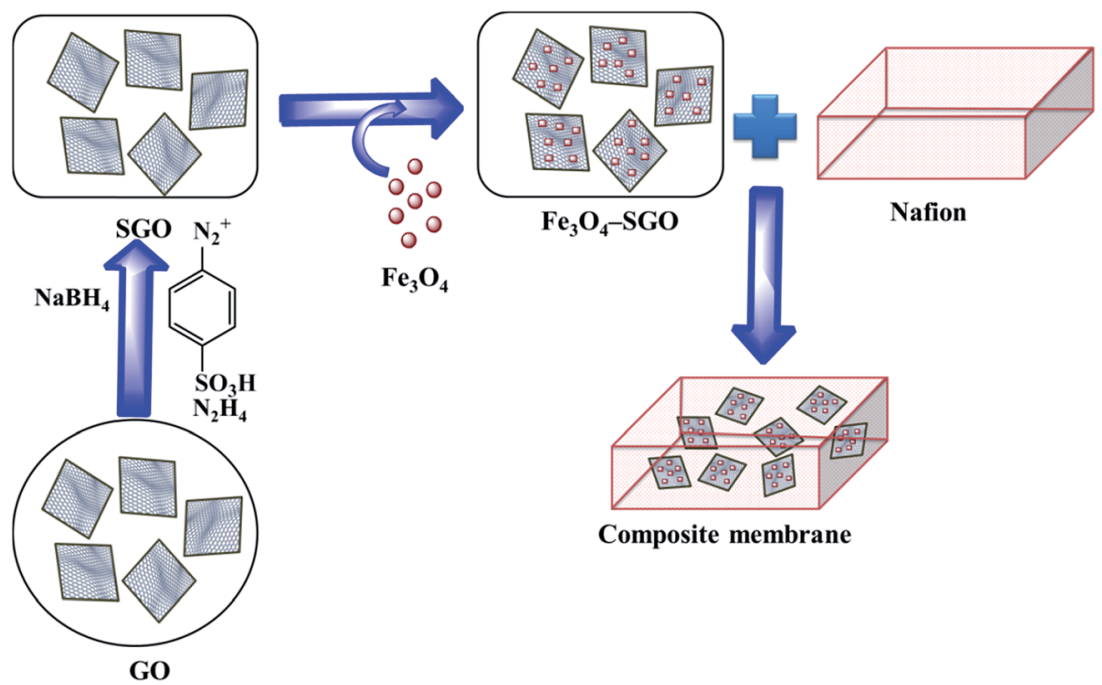

Scheme 1 Preparation process of Nafion/ $/ \mathrm{Fe}_{3} \mathrm{O}_{4}-\mathrm{SGO}$ composite membrane.

$$
\mu=\frac{1}{M N} \sum_{K \rightarrow 0}^{M-1} \sum_{l \rightarrow 0}^{N-1} Z\left(x_{k}-y_{l}\right) \text { is the mean height }
$$

Thermal stability of the membrane specimens was analyzed by TGA (Q50-TA instruments) from 30 to $800{ }^{\circ} \mathrm{C}$ at a heating rate of $5{ }^{\circ} \mathrm{C} \mathrm{min}{ }^{-1}$ under a nitrogen atmosphere. Thermomechanical stability of the membrane specimens was investigated by using a dynamic mechanical analyzer (DMA) (Q800-TA instruments) from 0 to $200{ }^{\circ} \mathrm{C}$ at a heating rate of $10{ }^{\circ} \mathrm{C} \mathrm{min}^{-1}$ under a nitrogen atmosphere.

\section{Measurements}

\subsection{Water uptake and dimensional stability}

Prior dried $\left(100{ }^{\circ} \mathrm{C}\right.$ for $\left.5 \mathrm{~h}\right)$ membrane specimens were measured for mass, length and thickness, and then submerged into DI water at $60^{\circ} \mathrm{C}$ for $24 \mathrm{~h}$ to attain equilibrium. Afterward, the water on the surface of membranes was carefully blotted with tissue paper and mass, length and thickness of membranes were measured again., ${ }^{5,28}$ The measurement was repeated three times for each membrane using different specimens, and the average value was used for calculation. \% of changes in mass, length and thickness were calculated using the eqn (3)-(5):

$$
\begin{aligned}
& \text { Change in mass }(\%)=\left[\frac{M_{\text {wet }}-M_{\text {dry }}}{M_{\text {dry }}}\right] 100 \\
& \text { Change in length }(\%)=\left[\frac{L_{\text {wet }}-L_{\text {dry }}}{L_{\text {dry }}}\right] 100 \\
& \text { Change in thickness }(\%)=\left[\frac{T_{\text {wet }}-T_{\text {dry }}}{T_{\text {dry }}}\right] 100
\end{aligned}
$$

where $M_{\text {wet }}, L_{\text {wet }}$ and $T_{\text {wet }}$ are the mass (mg), length (mm) and thickness $(\mu \mathrm{m})$ of wet membrane specimens, respectively, and $M_{\mathrm{dry}}, L_{\mathrm{dry}}$ and $T_{\mathrm{dry}}$ are the mass, length and thickness of dry membrane specimens, respectively.

\subsection{Water contact angle}

Wettability of the membrane specimens was measured by static water contact angle method. The measurement was performed at room temperature using a contact angle goniometer (DSA10, Kruss GmbH analyser, Germany). The detailed procedure of contact angle measurement can be found in the ref. 6 .

\subsection{Ion exchange capacity}

Ion exchange capacity (IEC) indicates the number of milliequivalents of ions present in $1 \mathrm{~g}$ of a dry membrane. ${ }^{17}$ The required amount of dry membrane specimen was equilibrated in $0.1 \mathrm{M} \mathrm{NaCl}$ for $24 \mathrm{~h}$ to exchange $\mathrm{H}^{+}$with $\mathrm{Na}^{+}$ions. The released $\mathrm{H}^{+}$ions were then titrated against $0.01 \mathrm{M}$ solution of $\mathrm{NaOH}$ using phenolphthalein as an indicator. By measuring the volume of $\mathrm{NaOH}$ consumed, the molar quantity of ionic sites containing $\mathrm{H}^{+}$ions was determined. The titration was repeated three times for each membrane using different specimens, and the average value was used for calculation. The IEC was calculated using the eqn (6):

$$
\begin{aligned}
& \text { IEC }\left(\text { meq. } \mathrm{g}^{-1}\right)= \\
& \frac{\text { volume of } \mathrm{NaOH} \text { consumed } \times \text { concentration of } \mathrm{NaOH}}{\text { weight of dry membrane specimen }}
\end{aligned}
$$

\subsection{Proton conductivity}

The proton conductivity of membrane specimens was measured in the longitudinal direction with a four-probe BekkTech cell by alternating current (AC) impedance method. ${ }^{35} \mathrm{~A}$ piece of membrane $(30 \mathrm{~mm} \times 5 \mathrm{~mm})$ was placed across the Pt probes, and membrane resistance $(R, \Omega)$ was measured using a frequency response analyzer (Scitech instrument conjugated with a Keithley-2400 source meter) as a function of temperature under low humidity. The proton conductivity $(\sigma)$ of membrane specimens was calculated using the eqn (7): 


$$
\sigma\left(\mathrm{mS} \mathrm{cm}^{-1}\right)=\frac{L}{R T W}
$$

where $L$ is the fixed distance between four Pt probes (i.e., 0.42 $\mathrm{cm}), R$ is the resistance (ohm) of the membrane specimen, and $T$ and $W$ are the respective thickness $(\mathrm{cm})$ and width $(\mathrm{cm})$ of the membrane specimen. The above mentioned measurement was repeated at least three times for each membrane using different specimens, and the average resistance value was used for calculation.

\subsection{Electrical conductivity}

The electrical conductivity of membrane specimens was measured using a four probe method. ${ }^{36}$ A piece of membrane $(30 \mathrm{~mm} \times 5 \mathrm{~mm})$ was placed across the Pt probes, and membrane resistance $(R, \Omega)$ was measured using a Keithley Electrometer as a function of applied voltage. The electrical conductivity $(\sigma)$ of membrane specimens can be calculated using the eqn (8):

$$
\left.\sigma(\mathrm{mS} \mathrm{cm})^{-1}\right)=\frac{G \times l}{A}
$$

where $G$ is the conductance (Siemens) of the membrane, $l$ is the thickness $(\mathrm{cm})$ of the membrane and $A$ is the active area $\left(\mathrm{cm}^{2}\right)$ of the membrane.

\subsection{Hydrogen $\left(\mathrm{H}_{2}\right)$ permeability}

$\mathrm{H}_{2}$-permeability measurements were carried out via traditional constant volume/variable pressure method at $30{ }^{\circ} \mathrm{C}$ under anhydrous condition. A detailed method of measuring the $\mathrm{H}_{2}$ permeability can be found in the ref. 37 . The measurement was repeated three times for each membrane using different specimens, and the average value was used for calculation. The $\mathrm{H}_{2}$ permeability was calculated using the eqn (9):

$$
\text { Permeability (barrer) }=D S=\frac{V_{\mathrm{p}} l\left(p_{\mathrm{p} 2}-p_{\mathrm{p} 1}\right)}{\left[A R T \Delta t\left(P_{\mathrm{f}}-\frac{p_{\mathrm{p} 2}+p_{\mathrm{p} 1}}{2}\right)\right]}
$$

where $D$ is the $\mathrm{H}_{2}$ gas diffusivity coefficient $\left(\mathrm{cm}^{2} \mathrm{~S}^{-1}\right), S\left(\mathrm{~cm}^{3}\right.$ $\left.\left(\mathrm{cm}^{2} \mathrm{~s} \mathrm{cmHg}\right)^{-1}\right)$ is the solubility coefficient, $V_{\mathrm{p}}$ is the constant permeation volume $\left(\mathrm{cm}^{3}\right), l$ is the film thickness $(\mathrm{cm}), A$ is the active membrane surface $\left(\mathrm{cm}^{2}\right), R$ is the gas universal constant $\left(\mathrm{J} \mathrm{mol}^{-1} \mathrm{~K}^{-1}\right.$ ), $T$ is the temperature $(\mathrm{K}), P_{\mathrm{f}}$ is the feed pressure ( $\mathrm{cmHg}$ ) and $\Delta t$ is the time taken for the pressure to change from $p_{\mathrm{p} 1}$ to $p_{\mathrm{p} 2}(\mathrm{sec})$.

\section{Fabrication of membrane electrode assembly (MEA) and evaluation of PEMFC performance}

Commercial gas diffusion electrodes (GDE; NARA Cell Tech, South Korea, thickness $=0.46 \mathrm{~mm}$ ) with Pt catalyst loading of $0.5 \mathrm{mg} \mathrm{cm}^{-1}$ were adopted to use as the electrodes in MEA fabrication. MEAs with an active electrode area of $2.5 \mathrm{~cm}^{2}$ were obtained by sandwiching membrane between gas diffusion electrodes and subsequent hot pressing under a pressure of 210 $\mathrm{kg} \mathrm{cm} \mathrm{cm}^{-2}$ at $110{ }^{\circ} \mathrm{C}$ for $3 \mathrm{~min} .{ }^{17,38}$ Each obtained MEAs were coupled with air tight Teflon gaskets and fixed in single cell fixture. PEMFC performance of MEAs was evaluated using Smart II (WonATech, South Korea) fuel cell test station. Flow rate of hydrogen and oxygen gases to their respective anode and cathode were fixed to be 450 and $600 \mathrm{~mL} \mathrm{~min}^{-1}$, respectively. The relative humidity of PEMFC depends upon the moisture content $\left(m \mathrm{H}_{2} \mathrm{O}\right)$, mass of water vapor $(D)$ and saturated vapor pressure of water $\left(P_{\text {sat }}\right)$. In order to attain desired relative humidity (i.e., $100 \%$ and $25 \%$ ), the parameters such as gas supply temperature (GST) and dew point humidification temperature (DPHT) were adjusted. After equilibrating the desired humidity level, the cell voltage was measured as a function of current density. The reproducibility of data was ensured by repeating the measurements at least twice with given set of conditions. All MEAs were evaluated in PEMFC atmospheric pressure without applying any back pressure.

\section{Results and discussion}

\subsection{Characterizations of GO, SGO and $\mathrm{Fe}_{3} \mathrm{O}_{4}-\mathrm{SGO}$}

FE-SEM and TEM images on surface morphologies of GO, SGO and $\mathrm{Fe}_{3} \mathrm{O}_{4}-\mathrm{SGO}$ are shown in Fig. 1a-f. GO exhibits the morphology of wavy, multilayered and wrinkled sheets (Fig. 1a and d), due to the intercalations of oxygen-related functionalities. In contrast, flat morphology is observed for SGO (Fig. 1b and e), because of the removal of oxygen-related functionalities via chemical reduction. In the case of $\mathrm{Fe}_{3} \mathrm{O}_{4}-\mathrm{SGO}$ composite, $\mathrm{Fe}_{3} \mathrm{O}_{4}$ nanoparticles ranging from 60 to $120 \mathrm{~nm}$ are densely anchored over the SGO sheets with homogeneous distribution (Fig. 1c and f), and no $\mathrm{Fe}_{3} \mathrm{O}_{4}$ nanoparticles scattered outside of the sheets, representing effectual combination between $\mathrm{Fe}_{3} \mathrm{O}_{4}$ and SGO. The electrostatic interactions exerted between $-\mathrm{OH}$ group of $\mathrm{Fe}_{3} \mathrm{O}_{4}$ and $-\mathrm{OH},-\mathrm{O}-,-\mathrm{CO}_{2} \mathrm{H}$ and $-\mathrm{SO}_{3} \mathrm{H}$ groups of SGO are responsible for dense anchoring of $\mathrm{Fe}_{3} \mathrm{O}_{4}$ over the SGO sheets. The obtained selected area electron diffraction (SAED) pattern (Fig. 1f-inset) ensured the poly-crystalline natured inverse cubic spinel structure of $\mathrm{Fe}_{3} \mathrm{O}_{4}$ nanoparticles. To investigate the crystalline structure of $\mathrm{GO}$, SGO and $\mathrm{Fe}_{3} \mathrm{O}_{4}-\mathrm{SGO}$, the XRD was performed and obtained diffraction patterns are presented in Fig. 2a. The characteristic peak of graphite observed at $26.32^{\circ}$ was disappeared and an intense peak observed at $11.56^{\circ}$ confirmed the formation of GO, which is ascribed to 001 plane. $^{39}$ The calculated interplanar distance of GO is $0.75 \mathrm{~nm}$, which is higher than that of graphite and is due to intercalation of oxygen-related functional groups. It can be seen that SGO exhibits the $2 \theta$ and interplanar distance of $24.38^{\circ}$ and $0.35 \mathrm{~nm}$, respectively. The interplanar distance of SGO is lower than that of GO and is due to the partial restacking of SGO sheets via $\pi-\pi$ interactions upon removal of oxygen functionalities. ${ }^{40}$ In the case of $\mathrm{Fe}_{3} \mathrm{O}_{4}-\mathrm{SGO}$ composite, a broad peak observed at $24.2^{\circ}$ is attributed to the 002 reflection plane of SGO, whereas the sharp peaks observed at 33.15, 35.87, 41.01, 54.06, 57.59 and 62.47 are attributed to the 200, 311, 400, 422, 511 and 440 facets of $\mathrm{Fe}_{3} \mathrm{O}_{4}$, respectively, which ensure the successful anchoring of $\mathrm{Fe}_{3} \mathrm{O}_{4}$ over the surface of SGO. D and G 


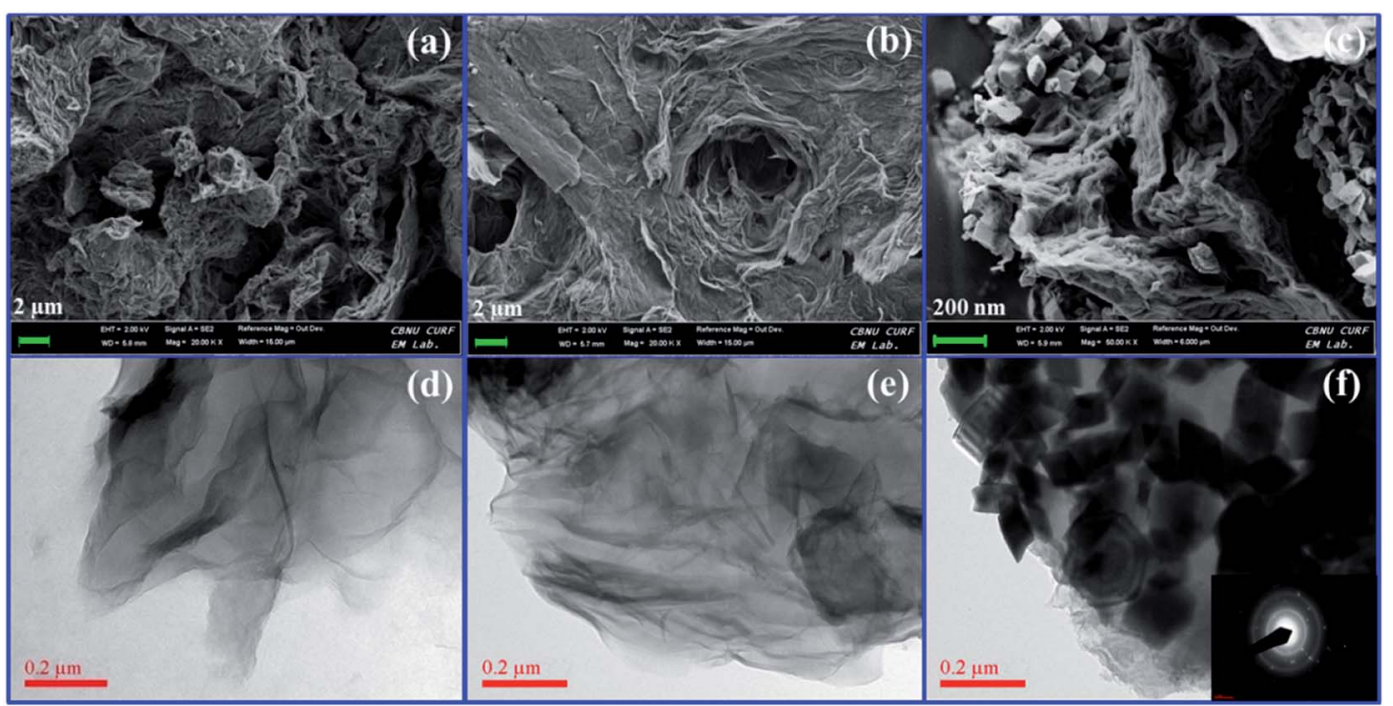

Fig. 1 FE-SEM images of (a) GO, (b) SGO and (c) $\mathrm{Fe}_{3} \mathrm{O}_{4}-\mathrm{SGO}$; TEM images of (d) GO, (e) $\mathrm{SGO}$ and (f) Fe $\mathrm{O}_{4}-\mathrm{SGO}$ and inset (f) SAED pattern.

bands are two significant features to characterize the Raman spectra of GO materials, which provide the information on structural defects, degree of disorders and carbon hybridization (Fig. 2b). ${ }^{41,42}$ The D band at $1359 \mathrm{~cm}^{-1}$ ascribes to the $\mathrm{A}_{1 \mathrm{~g}}$ vibration modes of $\mathrm{sp}^{3}$ hybridized disordered carbon lattice, while $\mathrm{G}$ band at $1591 \mathrm{~cm}^{-1}$ ascribes to the $\mathrm{E}_{2 \mathrm{~g}}$ mode of $\mathrm{sp}^{2}$ hybridized ordered carbon lattice. These bands specify that an intensive oxidation destroys the $\mathrm{sp}^{2}$ character and prompt the defects on carbon lattice. The intensity ratio $I_{\mathrm{D}} / I_{\mathrm{G}}$ of $\mathrm{GO}$ and SGO is 0.87 and 0.9 , respectively, which indicate the successful
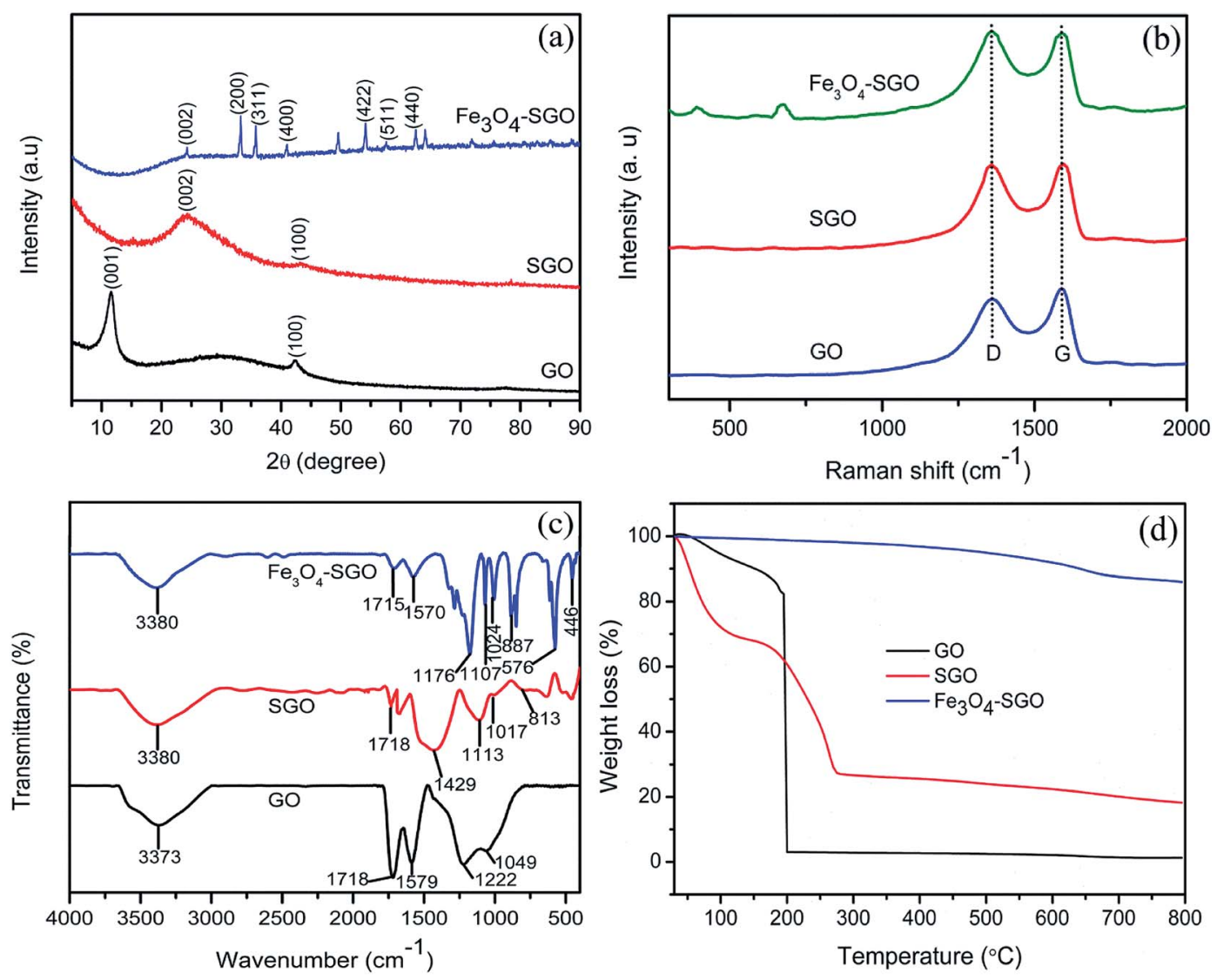

Fig. 2 (a) XRD patterns, (b) Raman spectra, (c) FT-IR spectra and (d) TGA curves of GO, SGO and $\mathrm{Fe}_{3} \mathrm{O}_{4}-\mathrm{SGO}$ 
reduction and functionalization of later by $-\mathrm{SO}_{3} \mathrm{H}$ containing organic moiety. In addition to the abovementioned carbon bands, an $\mathrm{A}_{1 \mathrm{~g}}$ mode of $\mathrm{Fe}_{3} \mathrm{O}_{4}$ can be found at $669 \mathrm{~cm}^{-1}$, confirming the composite structure of $\mathrm{Fe}_{3} \mathrm{O}_{4}$ with $\mathrm{SGO}$ sheets of $\mathrm{Fe}_{3} \mathrm{O}_{4}$-SGO solid proton conductor. Fig. 2c demonstrates the FT-IR spectra obtained at room temperature for GO, SGO and $\mathrm{Fe}_{3} \mathrm{O}_{4}$-SGO. GO oxidation from graphite was verified by the characteristic peaks at 3373, 1718, 1222 and $1049 \mathrm{~cm}^{-1}$, which are assigned to $-\mathrm{OH}$ (from intercalated water molecules), $\mathrm{C}=\mathrm{O}$ (from carboxylic acid group), $\mathrm{C}-\mathrm{OH}$ (from carboxylic acid group) and $\mathrm{C}-\mathrm{O}$ (from epoxy group) stretching, respectively. ${ }^{43-45}$ The peak appearing at $1579 \mathrm{~cm}^{-1}$ in GO is consistent with graphite, which is related to the stretching vibration of $\mathrm{C}=\mathrm{C}$ from unoxidized graphitic domains. ${ }^{28}$ Compared to GO, two significant peaks are observed for SGO at 1113 and $1017 \mathrm{~cm}^{-1}$, which are assigned to the respective symmetric and asymmetric stretching modes of $\mathrm{O}=\mathrm{S}=\mathrm{O}$ in $-\mathrm{SO}_{3} \mathrm{H}$ groups; the small peak appearing at $813 \mathrm{~cm}^{-1}$ is corresponding to the stretching vibration of $p$-disubstituted phenyl groups. The apparent reduction in stretching vibration of $\mathrm{C}=\mathrm{O}$ at $1718 \mathrm{~cm}^{-1}$ in FT-IR spectrum of SGO indicate the effective reduction of GO by present method. The presence of $\mathrm{Fe}_{3} \mathrm{O}_{4}$ in $\mathrm{Fe}_{3} \mathrm{O}_{4}-\mathrm{SGO}$ composite is confirmed from the bands found at 576 and $887 \mathrm{~cm}^{-1}$, owing to the stretching modes of $\mathrm{Fe}-\mathrm{O}, \mathrm{Fe}-\mathrm{O}-\mathrm{C}$, respectively. TGA profile of prepared nanostructures is given in the Fig. 2d. Two significant degradations are observed for GO as follows: (i) from 30 to $100{ }^{\circ} \mathrm{C}$ and (ii) from 100 to $203{ }^{\circ} \mathrm{C}$. The former one is due to the removal of moisture mainly physisorbed free water molecules. The later is because of elimination of oxygen-labile functional groups such as carboxyl, epoxy, hydroxyl and so forth. The quantity of oxygen-labile functional groups in GO is about $89.51 \%$ according to TGA analysis and the principal reason for excess weight loss at $200{ }^{\circ} \mathrm{C}$ is decomposition of carbon atoms of GO together with oxygen during thermal combustion process. ${ }^{\mathbf{4 2 , 4 6}}$ By comparison, an improved thermal stability is observed for SGO with a residual weight of $18.23 \%$, owing to the partial removal of oxygen-labile functional groups via chemical reduction. Notably, the second weight loss in SGO from 150 to $270{ }^{\circ} \mathrm{C}$ is $32.91 \%$ which verifies the sulfonation of GO to SGO. The removal of oxygen-related functionalities of $\mathrm{GO}$ by $\mathrm{NaBH}_{4}$ before sulfonation may lead to incorporate excess number of aryl diazonium salt of sulfanilic acid on GO. The thermal stability of SGO is further improved after anchoring $\mathrm{Fe}_{3} \mathrm{O}_{4}$ nanoparticles, as evidenced by higher residual weight of $\mathrm{Fe}_{3} \mathrm{O}_{4}-\mathrm{SGO}$ i.e., $86.03 \%$ and is due to the ceramic behavior of the corresponding composite given via $\mathrm{Fe}_{3} \mathrm{O}_{4}$ nanoparticles. The hydrolytic stability of $\mathrm{Fe}_{3} \mathrm{O}_{4}$ and $\mathrm{Fe}_{3} \mathrm{O}_{4}$-SGO composite was measured in $1 \mathrm{M}$ acidic solution at $70{ }^{\circ} \mathrm{C}$ to understand the dissolution of $\mathrm{Fe}_{3} \mathrm{O}_{4}$; details including figures and explanation, are provided in ESI. $\dagger$

\subsection{Characterizations of membranes}

6.2.1. Morphological properties. The internal morphology and filler dispersion of the composite membranes are significant factors in determining macroscopic properties such as water uptake, proton conductivity, mechanical strength and gas permeability. ${ }^{28}$ Surface and cross-sectional SEM images of pristine recast Nafion, Nafion/GO-3 and Nafion/SGF-3 are displayed in Fig. 3a-f. It can be observed that pristine Nafion exhibits a clean and smooth surface (Fig. 3a), while incorporation of GO (Fig. 3b) or $\mathrm{Fe}_{3} \mathrm{O}_{4}-\mathrm{SGO}$ (Fig. 3c) results in surface roughness, which is due to the crumpled behavior of fillers. Compared to pristine Nafion (Fig. 3d), the obvious wrinkles are observed throughout the cross section of Nafion/GO-3 (Fig. 3e) and Nafion/SGF-3 (Fig. 3f) membranes, which ensure the dispersion of fillers. Meanwhile, the $\mathrm{Fe}_{3} \mathrm{O}_{4}-\mathrm{SGO}$ fillers show a more uniform dispersion than GO within Nafion matrix as a result of strong interfacial interactions (hydrogen bonding) between $-\mathrm{OH},-\mathrm{O}-,-\mathrm{CO}_{2} \mathrm{H}$ and $-\mathrm{SO}_{3} \mathrm{H}$ groups of $\mathrm{Fe}_{3} \mathrm{O}_{4}-\mathrm{SGO}$ and $-\mathrm{SO}_{3} \mathrm{H}$ groups of Nafion, thereby increasing the mutual compatibility between fillers and Nafion matrix. In such a way, the co-continuous proton conducting channels are generated across the Nafion/SGF-3 membrane, which facilitate the proton conductivity. Scheme $\mathrm{S} 1$ ( $\mathrm{ESI} \dagger$ ) shows the possible interactions exerted between Nafion and $\mathrm{Fe}_{3} \mathrm{O}_{4}-\mathrm{SGO}$ in composite membrane. The water contact angle of Nafion/SGF-3 membrane is $87.21^{\circ}$ (Fig. 3c-inset), indicating the presence of hydrophilic surfaces due to the presence of polar groups such as $-\mathrm{OH},-\mathrm{O}-$ $-\mathrm{CO}_{2} \mathrm{H}$ and $-\mathrm{SO}_{3} \mathrm{H}$. The contact angle of the pristine Nafion membrane was $103.56^{\circ}$ (Fig. 3a-inset). However, this value was reduced to $87.21^{\circ}$ after incorporating $3 \mathrm{wt} \% \mathrm{Fe}_{3} \mathrm{O}_{4}-\mathrm{SGO}$, indicating an enhancement in hydrophilicity due to an increase in the aforementioned polar groups. The peak found at about 6.3 $\mathrm{keV}$ (due to $\mathrm{Fe}$ ) in the EDX spectrum of Nafion/SGF-3 membrane (Fig. 3h) confirms the incorporation of $\mathrm{Fe}_{3} \mathrm{O}_{4}-\mathrm{SGO}$ in the Nafion matrix. The density and distribution of $\mathrm{Fe}_{3} \mathrm{O}_{4}-\mathrm{SGO}$ in the Nafion matrix were also examined by quantitative energy dispersive elemental mapping. It can be seen that $\mathrm{Fe}_{3} \mathrm{O}_{4}-\mathrm{SGO}$ is uniformly distributed on the entire cross section of Nafion rather than only being located at a particular site (Fig. 4f), which helps to improve the proton conductivity and mechanical stability of composite membranes. 2D and 3D AFM topographies and lines profiles of pristine recast Nafion, Nafion/GO-3 and Nafion/SGF-3 membranes are provided in Fig. 5. The image size of each membrane is $5 \mu \mathrm{m} \times 5 \mu \mathrm{m}$. Bright and dark regions in the topographies represent the height variations on the membranes. The topography exhibits significant morphological difference on the Nafion membrane before and after incorporating $\mathrm{GO}$ or $\mathrm{Fe}_{3} \mathrm{O}_{4}$-SGO. Pristine Nafion exhibits a detailed structure with randomly distributed irregular spikes (approximately 100-260 $\mathrm{nm}$ width and 1-13 $\mathrm{nm}$ height), while the subsidence and protrusions are distributed on the surface of Nafion/GO-3 (approximately 100-960 nm width and 1-90 nm height) and Nafion/SGF-3 (approximately 100-600 nm width and 1-86 nm height) membranes. Detailed structure with spikes might be partially hidden on the surface of composite membranes because the subsidence and protrusions are relatively higher than spikes. The RMS roughness of above specified membranes was calculated by eqn (1). The RMS roughness of pristine Nafion is approximately $1 \mathrm{~nm}$, similar to uniform polymer membrane reported in the literature. ${ }^{17}$ However, the RMS roughness of Nafion/GO-3 and Nafion/SGF-3 membranes is approximately 10 and $12 \mathrm{~nm}$, respectively. It is noteworthy 


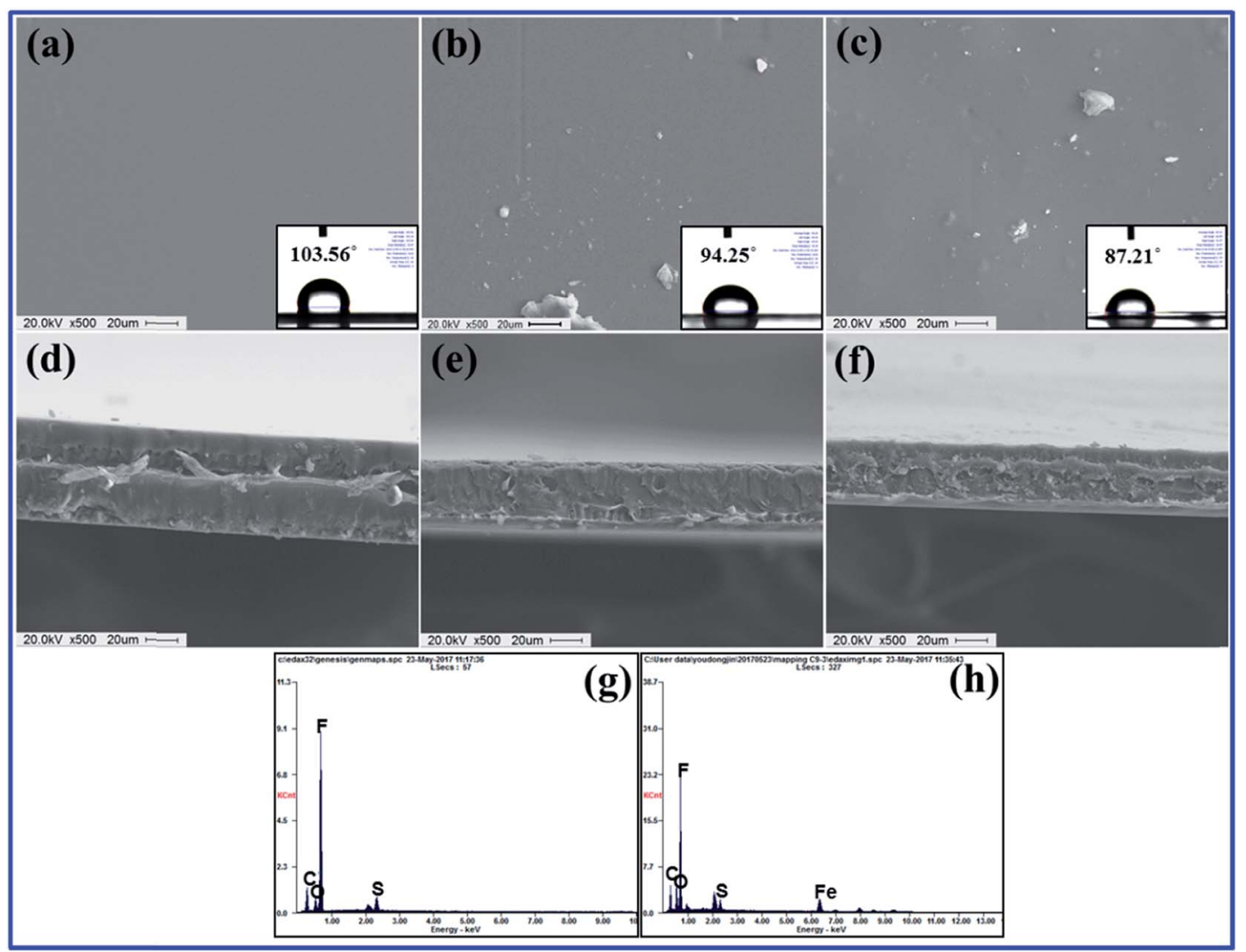

Fig. 3 Surface SEM images of membranes of (a) pristine recast Nafion, (b) Nafion/GO-3 and (c) Nafion/SGF-3; insets of (a), (b) and (c) corresponding water contact angle images; cross-sectional SEM images of membranes of (d) pristine recast Nafion, (e) Nafion/GO-3 and (f) Nafion/ SGF-3; EDX spectra of (g) pristine recast Nafion and (h) Nafion/SGF-3.

that extended surface area of $\mathrm{GO}$ or $\mathrm{Fe}_{3} \mathrm{O}_{4}-\mathrm{SGO}$ with wrinkled features is responsible for high RMS roughness of composite membranes. This appears to be advantageous toward more water uptake capacity and high compatibility with the electrode during fabrication of membrane electrode assembly.

6.2.2. Thermomechanical stabilities. Thermal stability of pristine recast Nafion, Nafion/GO-3 and Nafion/SGF-3 was studied by TGA to explore the effects of filler-polymer interactions, and obtained thermographs are demonstrated in Fig. 6a. Pristine Nafion and composite membranes depicted similar three step weight drops: (i) from 30 to $100{ }^{\circ} \mathrm{C}$ that is due to the loss of free water molecules from membranes, (ii) from 240 to $400{ }^{\circ} \mathrm{C}$ that is due to the decomposition of $-\mathrm{SO}_{3} \mathrm{H}$ groups in the side chain of the membranes and (iii) above $400{ }^{\circ} \mathrm{C}$ that is because of disintegration of the aliphatic backbones of polymer. It is noteworthy that thermal degradation of composite membranes delays throughout the study and is more pronounced in the temperature range from 400 to $800{ }^{\circ} \mathrm{C}$. Composite membranes showed lower weight drops than pristine Nafion membrane, demonstrating that the addition of GO or $\mathrm{Fe}_{3} \mathrm{O}_{4}-\mathrm{SGO}$ effectively improved the thermal stability of Nafion by prohibiting the movement of aliphatic backbones through interfacial interactions. At $800{ }^{\circ} \mathrm{C}$, the pristine Nafion showed a residual weight of $0.26 \%$, whereas Nafion/GO-3 and Nafion/SGF-3 membranes exhibited the residual weights of 2.89 and $8.24 \%$, respectively. The higher residual weight in composite membranes is a clear manifestation for higher thermal stability of composite membrane containing GO or $\mathrm{Fe}_{3} \mathrm{O}_{4}$-SGO. Temperature dependent mechanical properties of pristine recast Nafion and optimized Nafion/GO-3 and Nafion/ SGF-3 composite membranes are shown in Fig. 6b. It was found that the maximum value of storage modulus to be $1135 \mathrm{MPa}$ for Nafion/SGF-3 membrane, which is almost 1.87 fold higher than that of Nafion/GO-3 membrane and 3.16 fold higher than that of pristine Nafion membrane. The enhancement in the mechanical strength of Nafion/SGF-3 membrane indicates strong hydrogen bonding interactions due the presence of common $-\mathrm{SO}_{3} \mathrm{H}$ groups in $\mathrm{SGO}$ and Nafion, which strictly restrict the reorganization of polymer chains and toughen the membrane up to a reasonable margin. The $\mathrm{Fe}_{3} \mathrm{O}_{4}$ nanoparticles over the SGO sheets help to increase adhesion of fillers with host matrix, which further toughens the membrane. Accordingly, Nafion/SGF-3 composite membrane is extremely beneficial for high temperature and low humidity PEMFC operation.

6.2.3. Water uptake, dimensional stability, hydration number and IEC. Percentage of mass, length and thickness change in membrane after immersing in water at $60^{\circ} \mathrm{C}$ for $24 \mathrm{~h}$ referred to as the water uptake and dimensional stability as shown in Table 1. It can be seen that pristine Nafion membrane has $26.34 \%$ water uptake, whereas Nafion/GO-3 and Nafion/ SGF-3 membranes have 31.24 and $35.63 \%$ water uptake, 


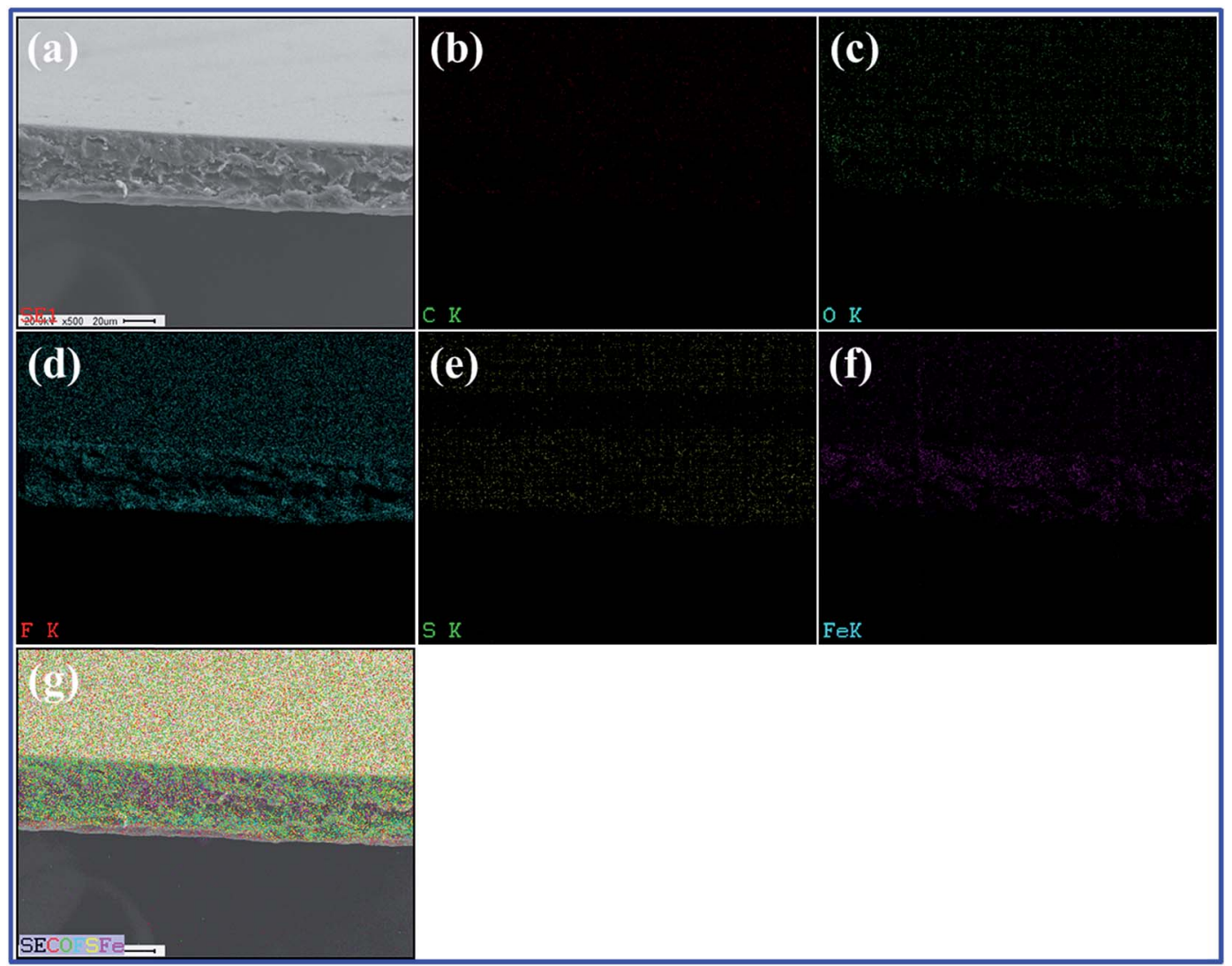

Fig. 4 (a) SEM image of selected area of Nafion/SGF-3; corresponding elemental mappings of (b) carbon, (c) oxygen, (d) fluorine, (e) sulfur, (f) iron and $(\mathrm{g})$ overlapping of elements.

respectively. By incorporating $\mathrm{GO}$ or $\mathrm{Fe}_{3} \mathrm{O}_{4}$-SGO filler, the membrane surface turns to more hydrophilic and is responsible to higher water uptake of corresponding composite membrane. The formation of hydrogen bonds between $-\mathrm{OH},-\mathrm{O}-$ and $-\mathrm{CO}_{2} \mathrm{H}$ groups of high surface fillers and free water molecules help to increase water uptake of Nafion/GO-3 and Nafion/SGF-3 membranes. Then, improvement in water uptake of the GO and $\mathrm{Fe}_{3} \mathrm{O}_{4}$-SGO based membranes can increase the proton conductivity of corresponding membranes. Water uptake of Nafion/SGF-X membrane is found to be increased from 26.34 to $35.63 \%$ upon increasing the filler from 0 to $3 \mathrm{wt} \%$, however, kinetics of water uptake decrease in $3 \mathrm{wt} \%$, which is probably due to the increasing adhesion at polymer-filler interface. The addition of $\mathrm{GO}$ or $\mathrm{Fe}_{3} \mathrm{O}_{4}$-SGO also improved the in-plane dimensional stability of membrane during hydration without affecting the water uptake significantly. Pristine Nafion membrane exhibits $17.31 \%$ swelling in length direction, whereas the membrane containing optimized wt $\%$ GO or $\mathrm{Fe}_{3} \mathrm{O}_{4}$-SGO show 11.22 and $11.88 \%$ swelling, respectively. It is assumed that during solution casting, the fillers are perpendicularly oriented to the cross section of the membranes, which restricts the relaxation of polymer chains in lateral direction. Then, improvement in in-plane dimensional stability can reduce the delamination of composite membranes from electrodes during PEMFC operation and enhance the cell performance. An increase in swelling in the thickness direction of membrane was also observed upon addition of fillers. This sort of membrane swelling can cause increased pressure between MEA and bipolar plates; however, it can be compensated by compression of the bipolar plates. Collectively, the improvement in water retention capacity without significantly affecting the dimensional stability enables the composite membranes to be well-suited for repeatable PEFC operations. IEC value is considered to correspond to the density of functional groups in the PEMs. ${ }^{47,48}$ Table 1 lists the IEC value of all prepared membranes. IEC for the pristine Nafion membrane was 0.89 meq. $\mathrm{g}^{-1}$, which was lower than the IECs of Nafion/GO-3 (1.03 meq. $\mathrm{g}^{-1}$ ), and Nafion/SGF-3 (1.36 meq. $\mathrm{g}^{-1}$ ). The IEC of the Nafion membrane increases with addition of $\mathrm{GO}$ or $\mathrm{Fe}_{3} \mathrm{O}_{4}-$ SGO. This is due to the SGO contained high density of $-\mathrm{SO}_{3} \mathrm{H}$ groups and $\mathrm{Fe}_{3} \mathrm{O}_{4}$ contained high density of $-\mathrm{OH}$ groups. The number of water molecules absorbed per unit volume of $-\mathrm{SO}_{3} \mathrm{H}$ groups is defined as hydration number $(\lambda) .^{36,40,49}$ This was calculated using the eqn (10):

$$
\lambda=\left[\frac{\text { water uptake }}{18.01}\right]\left[\frac{10}{\mathrm{IEC}}\right]
$$

where 18.01 is the molecular weight of water in $\mathrm{g} \mathrm{mol}^{-1}$.

It can be observed that by incorporating $3 \mathrm{wt} \%$ GO into the Nafion, the $\lambda$ value increased from 16.40 to 16.79 , which is again due to the high density of functional groups in the composite membranes provided by high surface GO. However, $\lambda$ value 


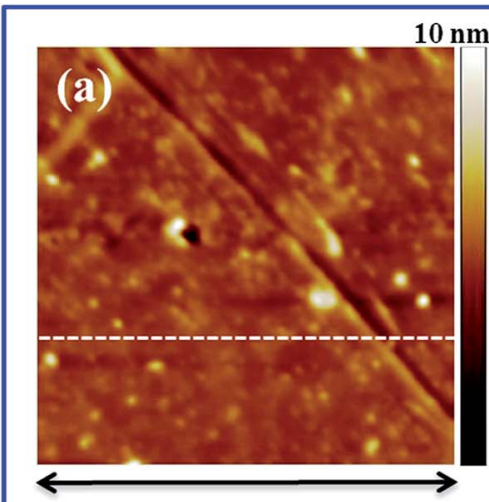

$5.0 \mu \mathrm{m}$

(d)
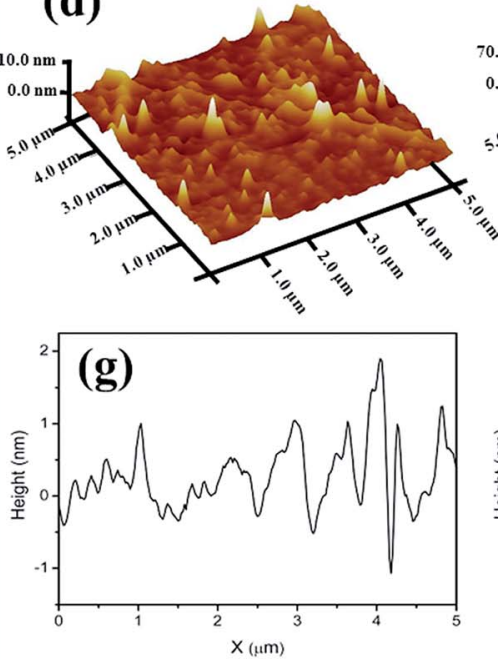

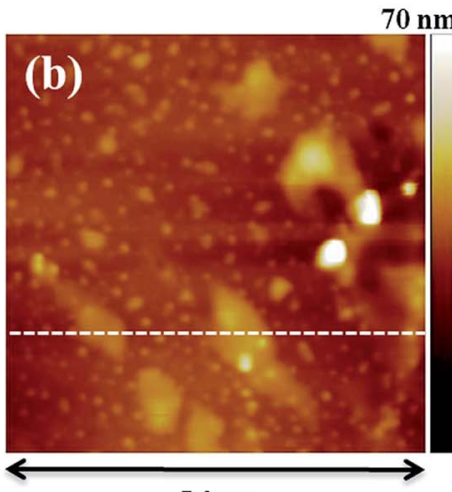

$5.0 \mu \mathrm{m}$

(e)
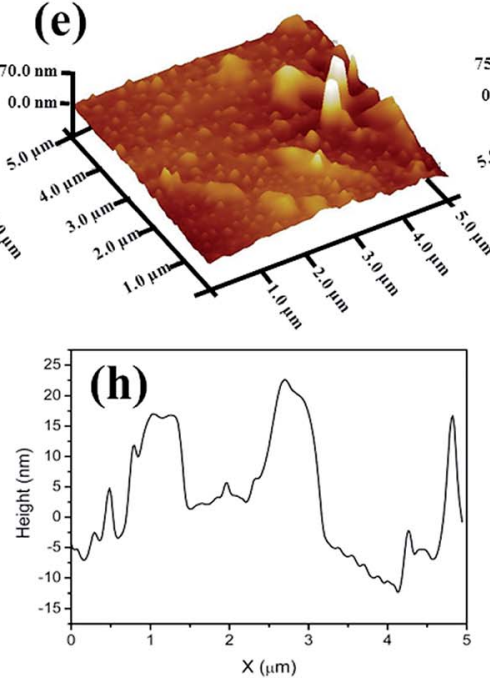

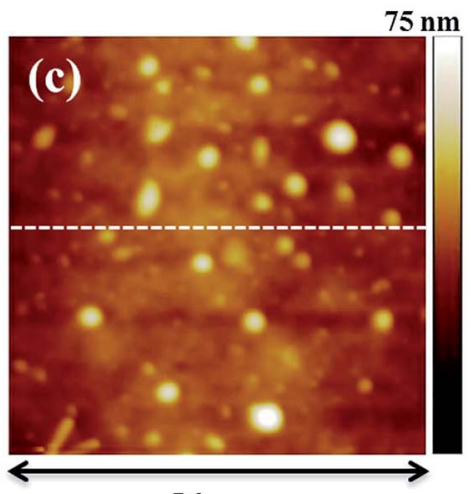

$5.0 \mu \mathrm{m}$
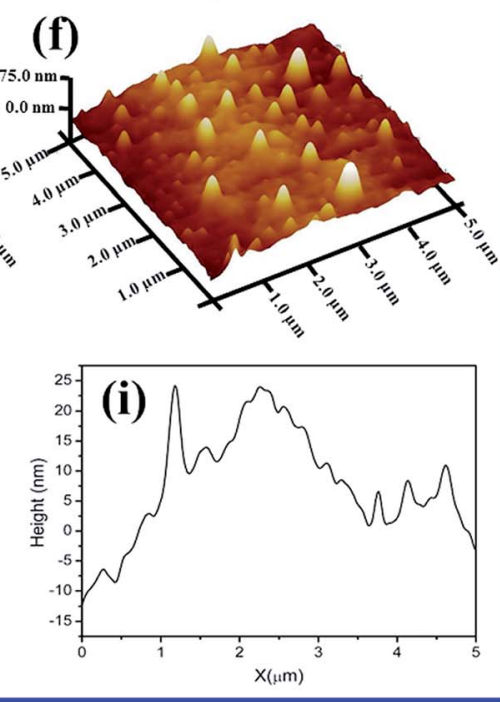

Fig. 5 2D AFM images of membranes of (a) pristine recast Nafion, (b) Nafion/GO-3 and (c) Nafion/SGF-3; 3D AFM images of membranes of (d) pristine recast Nafion, (e) Nafion/GO-3 and (f) Nafion/SGF-3; line profiles of membranes of (g) pristine recast Nafion, (h) Nafion/GO-3 and (i) Nafion/SGF-3.

decreased from 16.40 to 14.48 by incorporating 3 wt $\% \mathrm{Fe}_{3} \mathrm{O}_{4}-$ SGO into the Nafion. The decrease in $\lambda$ of Nafion/SGF-3 membrane can be attributed to the compact structure of membrane due to hydrogen bonding between surface $-\mathrm{OH}$ groups of $\mathrm{Fe}_{3} \mathrm{O}_{4}$ and $-\mathrm{F}$ and $-\mathrm{SO}_{3} \mathrm{H}$ groups of Nafion.
6.2.4. Proton conductivity and Arrhenius plot. As a key parameter to PEMs, the proton conductivities of membrane specimens were measured at different temperatures under $100 \%$ and $20 \%$ RH. Fig. 7a shows the all obtained proton conductivities of membrane specimens under $100 \% \mathrm{RH}$. It can
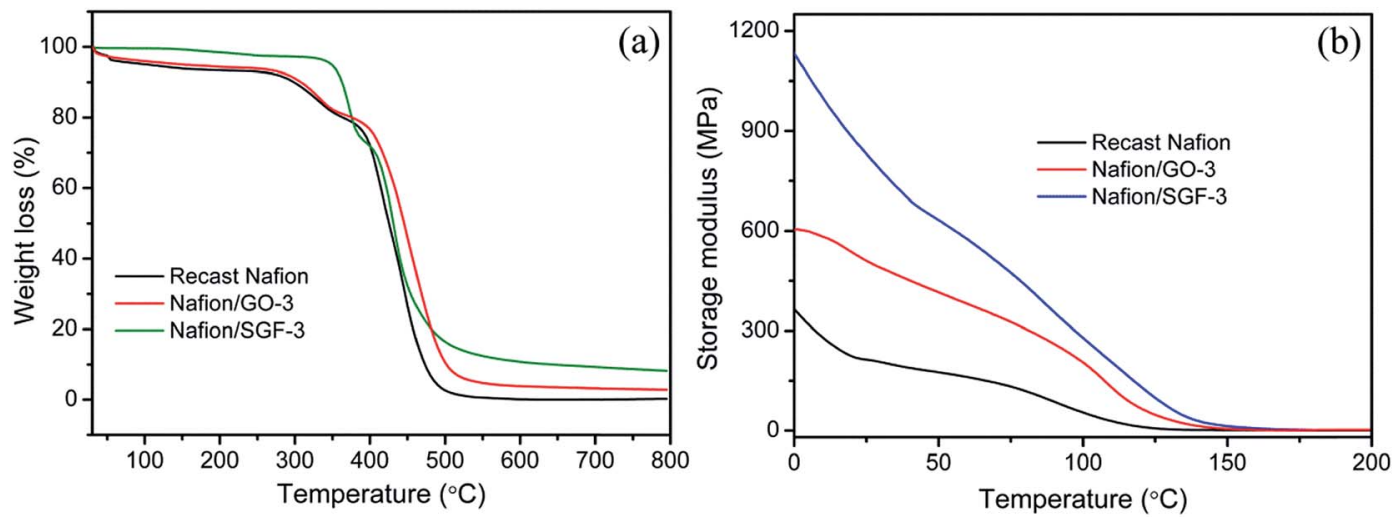

Fig. 6 (a) TGA and (b) DMA curves of pristine recast Nafion and composite membranes. 
Table 1 lon exchange capacity, water uptake, length change, thickness change, hydration number and proton conductivity values of different composite membranes

\begin{tabular}{|c|c|c|c|c|c|}
\hline Recast Nafion & 0.89 & $26.34 \pm 2$ & $17.31 \pm 1$ & $6.13 \pm 2$ & 16.40 \\
\hline Nafion/SGF-1.5 & 1.12 & $33.36 \pm 2$ & $14.18 \pm 3$ & $11.95 \pm 2$ & 16.51 \\
\hline Nafion/SGF-3 & 1.36 & $35.63 \pm 3$ & $11.88 \pm 2$ & $15.79 \pm 3$ & 14.48 \\
\hline Nafion/GO-3 & 1.03 & $31.24 \pm 1$ & $11.22 \pm 3$ & $13.35 \pm 2$ & 16.79 \\
\hline
\end{tabular}

be observed that pristine Nafion specimen exhibited a proton conductivity of $36.67 \mathrm{mS} \mathrm{cm}^{-1}$ at $30{ }^{\circ} \mathrm{C}$, which increase with temperature and reached a peak value of $85.71 \mathrm{mS} \mathrm{cm}^{-1}$ at $90^{\circ} \mathrm{C}$. The increased proton conductivity obtained is due to the rapid proton movement at high temperature. The transport of protons is relied on the two different mechanisms: (i) vehicular mechanism and (ii) Grotthuss mechanism. ${ }^{50,51}$ In GO based membrane, the $-\mathrm{OH}$ and $-\mathrm{CO}_{2} \mathrm{H}$ groups can attach to the free water molecules and increase the proton transport of membrane with vehicular mechanism. In $\mathrm{Fe}_{3} \mathrm{O}_{4}-\mathrm{SGO}$ based membrane, the $-\mathrm{SO}_{3} \mathrm{H}$ groups of $\mathrm{SGO}$ increase the bound water in membrane and encourage the proton diffusion from one ionic site $\left(\mathrm{H}_{3} \mathrm{O}^{+} \mathrm{SO}_{3}{ }^{-}\right)$to another ionic site via Grotthuss mechanism, and also hydrogen bonding between the $-\mathrm{OH}$ groups of $\mathrm{Fe}_{3} \mathrm{O}_{4}$ nanoparticles and free water molecules in membrane encourage the proton conductivity via vehicular mechanism. Since, incorporation of high surface $\mathrm{GO}$ or $\mathrm{Fe}_{3} \mathrm{O}_{4}{ }^{-}$ SGO in Nafion matrix is found to be enhanced the water uptake and IEC up to a reasonable margin, which consequently enhance the proton conductivity of composite membranes. Peak proton conductivities delivered by the Nafion/GO-3 and Nafion/SGF-3 specimens are 112.63 and $137.39 \mathrm{mS} \mathrm{cm}{ }^{-1}$ at $90{ }^{\circ} \mathrm{C}$, which are 1.31 and 1.61 folds higher than that of a pristine Nafion membrane, respectively. On the other side, peak proton conductivity of Nafion/SGF-X specimens is found to be increased from 85.71 to $137.39 \mathrm{mS} \mathrm{cm}{ }^{-1}$ on increasing the $\mathrm{Fe}_{3} \mathrm{O}_{4}-\mathrm{SGO}$ content from 0 to $3 \mathrm{wt} \%$, which may be due to the increase number of $-\mathrm{SO}_{3} \mathrm{H}$ groups per cluster volume of a domain. Fig. $7 \mathrm{c}$ shows all obtained proton conductivities of membrane specimens under $20 \% \mathrm{RH}$. These conductivity values are many folds
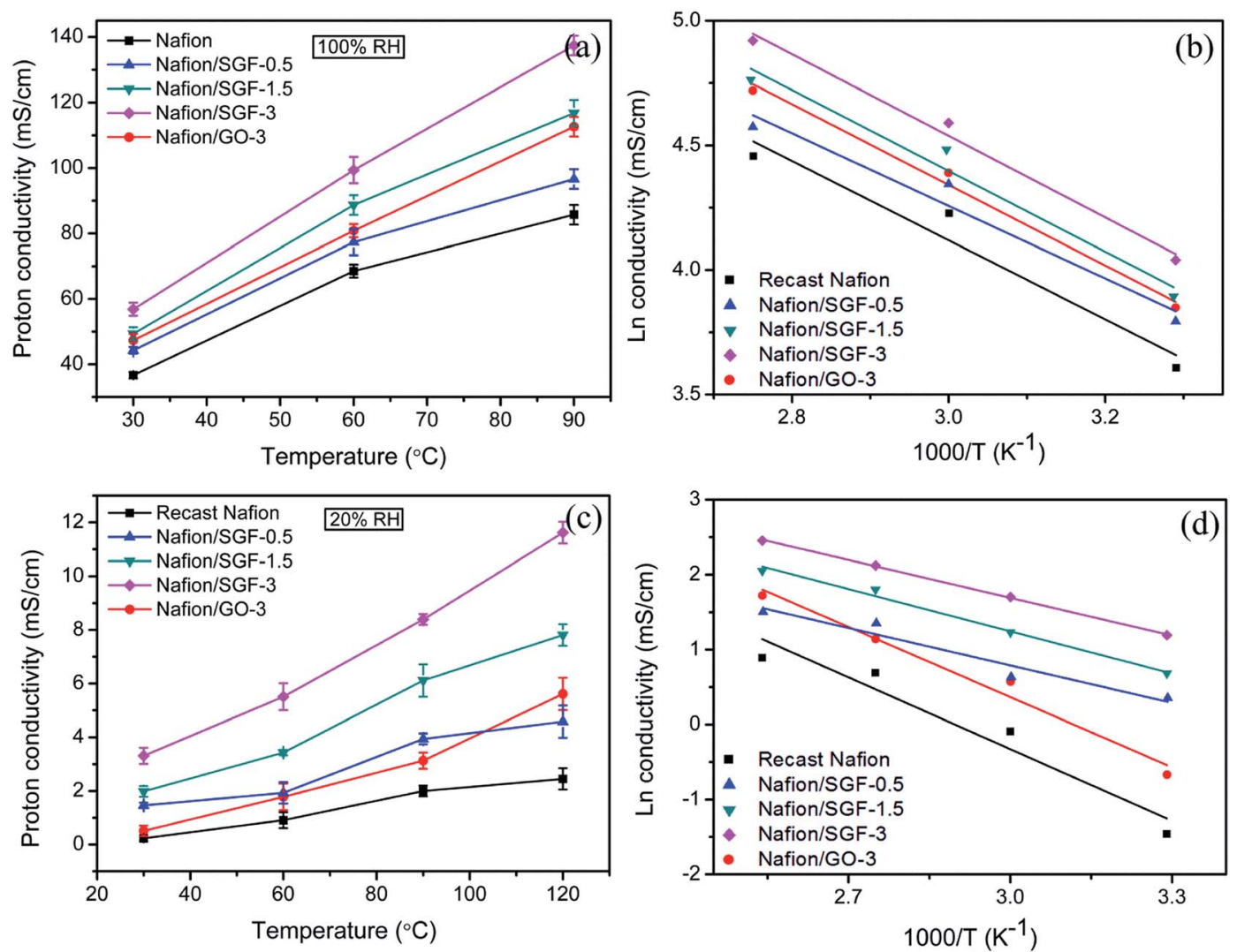

Fig. 7 Temperature variant proton conductivities of pristine recast Nafion and composite membranes (a) under $100 \% \mathrm{RH}$ and (c) under $20 \% \mathrm{RH}$; corresponding Arrhenius plots of proton conductivities (b) under $100 \% \mathrm{RH}$ and (d) under $20 \% \mathrm{RH}$. 
lower in relation to the conductivity values obtained under $100 \%$ $\mathrm{RH}$, which demonstrates the critical role of water molecules in proton conduction. At $120{ }^{\circ} \mathrm{C}$, the peak proton conductivity yielded by the pristine Nafion, Nafion/GO-3 and Nafion/SGF-3 specimens is $2.45,5.61$ and $11.62 \mathrm{mS} \mathrm{cm}^{-1}$, respectively. The lower conductivity of Nafion is due to the severe membrane dehydration caused by insufficient volume of bound water molecules, which could be successfully remediated by incorporating the $\mathrm{GO}$ or $\mathrm{Fe}_{3} \mathrm{O}_{4}-\mathrm{SGO}$ into the membrane.

The activation energy $\left(E_{\mathrm{a}}\right)$ required for the protons to travel through fabricated membranes was estimated using the Arrhenius eqn (11), as reported in the ref. 52 and 53.

$$
\ln \sigma=\ln \sigma_{0}-\frac{E_{\mathrm{a}}}{R T}
$$

here, $\sigma$ and $\sigma_{0}$ are the values of the conductivity and preexponential factor, respectively, in $\mathrm{mS} \mathrm{cm}^{-1}, E_{\mathrm{a}}$ is the activation energy required for protons to travel in $\mathrm{kJ} \mathrm{mol}^{-1}, R$ is the gas constant in $\mathrm{J} \mathrm{mol}^{-1} \mathrm{~K}^{-1}$, and $T$ is the absolute temperature in $\mathrm{K}$. The $E_{\mathrm{a}}$ of Nafion membrane decreased after incorporating $\mathrm{Fe}_{3} \mathrm{O}_{4}$-SGO (Table 2), demonstrating the high density of $-\mathrm{SO}_{3} \mathrm{H}$ and other hydrophilic groups were effectually dissociated throughout the Nafion/SGF-X membranes. Considering the $E_{\text {a }}$ for vehicular mechanism is $16.4 \mathrm{~kJ} \mathrm{~mol}^{-1}$ while that for Grotthuss mechanism is between 9.65 and $38.59 \mathrm{~kJ} \mathrm{~mol}^{-1}$.4,55 $^{54}$ The results obtained show that both vehicular and Grotthuss mechanisms coexist in the membranes under $100 \% \mathrm{RH}$, whereas Grotthuss mechanism dominates more under low humidity, due to lack of free water molecules.

6.2.5. Electrical conductivity. Fig. 8a shows the currentvoltage $(i-v)$ characteristics of the pristine recast Nafion, Nafion/ GO-3 and Nafion/SGF-3 membranes. Compared with pristine Nafion, there is significant change observed in $i-v$ characteristics of the composite membranes. Nafion membrane reveals negligible currents at all applied voltages from -10 to $10 \mathrm{~V}$, whereas current of the composite membranes increase as increase the voltage, due to the electrically conducting fillers i.e., $\mathrm{GO}$ and $\mathrm{Fe}_{3} \mathrm{O}_{4}-\mathrm{SGO}$. The calculated electrical conductivity for the Nafion/SGF-3 membrane $\left(0.37 \mathrm{mS} \mathrm{cm}^{-1}\right)$ is 3.08 fold higher than that of Nafion/GO-3 $\left(0.12 \mathrm{mS} \mathrm{cm}^{-1}\right)$ and 17.61 fold higher than that of pristine Nafion membrane $\left(0.021 \mathrm{mS} \mathrm{cm}^{-1}\right)$, due to high electrical conductivity and percolation threshold of $\mathrm{Fe}_{3} \mathrm{O}_{4}$-SGO. ${ }^{2}$ However, the obtained electrical conductivity of the Nafion $/ \mathrm{Fe}_{3} \mathrm{O}_{4}-\mathrm{SGO}$ membrane is generally less i.e., lesser than the level which can affect the open circuit voltage of membrane during PEMFC operation.
6.2.6. $\mathrm{H}_{2}$ permeability. The $\mathrm{H}_{2}$ permeability data for pristine Nafion and composite membranes are shown in Fig. 8b. The higher $\mathrm{H}_{2}$ permeability indicates higher $\mathrm{H}_{2}$ crossover through the membrane. $\mathrm{H}_{2}$ crossover for the Nafion/GO-3 membrane was 9.13 barrer, which was only $52.86 \%$ that of pristine Nafion membrane. The reduction in $\mathrm{H}_{2}$ crossover was ascribed to the presence of GO, which made the membrane compact and dense. In the case of Nafion/SGF-3 membrane, the $\mathrm{Fe}_{3} \mathrm{O}_{4}$-SGO fillers were tightly wrapped with the aliphatic chains of polymers through interfacial hydrogen bonding, which generate complex structures throughout the cross-section of the membrane. These complex structures exhibit a tortuous path for the diffusion of $\mathrm{H}_{2}$ gas molecules. Therefore, the Nafion/ SGF-3 membrane exhibits a further low $\mathrm{H}_{2}$ crossover compared to Nafion/GO-3 membrane.

6.2.7. PEMFC performance. Fig. $8 \mathrm{c}$ shows the polarization and power density curves of PEMFC containing pristine Nafion and Nafion/SGF-3 membranes. The PEMFC performances were measured: (i) at $70{ }^{\circ} \mathrm{C}$ under $100 \% \mathrm{RH}$ and (ii) at $120{ }^{\circ} \mathrm{C}$ under $25 \% \mathrm{RH}$. At the first condition, the open circuit voltage (OCV) of Nafion/SGF-3 membrane begins from above $1 \mathrm{~V}$, indicating that there is no electronic conductivity effect due to the existence of a small amount of $\mathrm{Fe}_{3} \mathrm{O}_{4}-\mathrm{SGO}$ in Nafion matrix. Peak power density of $636.58 \mathrm{~mW} \mathrm{~cm}^{-2}$ at a load current density of $1258 \mathrm{~mA} \mathrm{~cm}^{-2}$ was attained by the PEMFC containing pristine Nafion membrane, whereas the PEMFC containing Nafion/SGF-3 exhibited a peak power density of $783.69 \mathrm{~mW} \mathrm{~cm}^{-2}$ at a load current density of 1589 $\mathrm{mA} \mathrm{cm}{ }^{-2}$. The high performance of Nafion/SGF-3 membrane is primarily due to the high proton conductivity along with enhanced water uptake, attained by high density of $-\mathrm{SO}_{3} \mathrm{H}$ and $-\mathrm{OH}$ groups on $\mathrm{Fe}_{3} \mathrm{O}_{4}-\mathrm{SGO}$. Also, improvements were found in the ohmic and mass transport regions of the Nafion/ SGF-3 membrane when compared to the pristine Nafion, demonstrating that this membrane has high efficacy for the free flow of protons and supply of ions to the cathode reaction sites. At the second condition (nearer dry condition), the PEMFC containing pristine Nafion and Nafion/SGF-3 yielded peak power densities of 144.89 and $258.82 \mathrm{~mW} \mathrm{~cm}^{-2}$ at the load current densities of 431.36 and $640.73 \mathrm{~mA} \mathrm{~cm}$, respectively. In pristine Nafion case, due to the limited availability of water in membrane, the electro-osmotic drag of water from the anode to cathode and inadequate back diffusion of water from the cathode to anode cause the MEA to dehydrate. MEA dehydration results in an increase of ohmic resistance, leading to reduced cell performance. By contrast,

Table 2 Proton conductivity and activation energy values of different composite membranes

\begin{tabular}{llccc}
\hline Membrane & $\begin{array}{l}\text { Proton conductivity } \\
\left(\mathrm{mS} \mathrm{cm}^{-1}\right) \text { at } 60{ }^{\circ} \mathrm{C}\end{array}$ & $\begin{array}{l}\text { Proton conductivity } \\
\left.(\mathrm{mS} \mathrm{cm})^{-1}\right) \text { at } 120^{\circ} \mathrm{C}\end{array}$ & $\begin{array}{l}\text { Activation energy } \\
\left(\mathrm{kJ} \mathrm{mol}^{-1}\right) \text { under } 100 \% \mathrm{RH}\end{array}$ & $\begin{array}{l}\text { Activation energy } \\
\left.(\mathrm{kJ} \mathrm{mol})^{-1}\right) \mathrm{under} \mathrm{20 \%} \mathrm{RH}\end{array}$ \\
\hline Recast Nafion & $68.53 \pm 2$ & $2.45 \pm 0.4$ & 14.73 & 26.52 \\
Nafion/SGF-0.5 & $77.33 \pm 4$ & $4.58 \pm 0.6$ & 13.55 & 25.95 \\
Nafion/SGF-1.5 & $86.66 \pm 3$ & $7.81 \pm 0.4$ & 12.05 & 23.21 \\
Nafion/SGF-3 & $99.34 \pm 4$ & $11.62 \pm 0.4$ & 10.16 & 21.41 \\
Nafion/GO-3 & $80.82 \pm 2$ & $5.61 \pm 0.6$ & 13.28 & 19.22
\end{tabular}



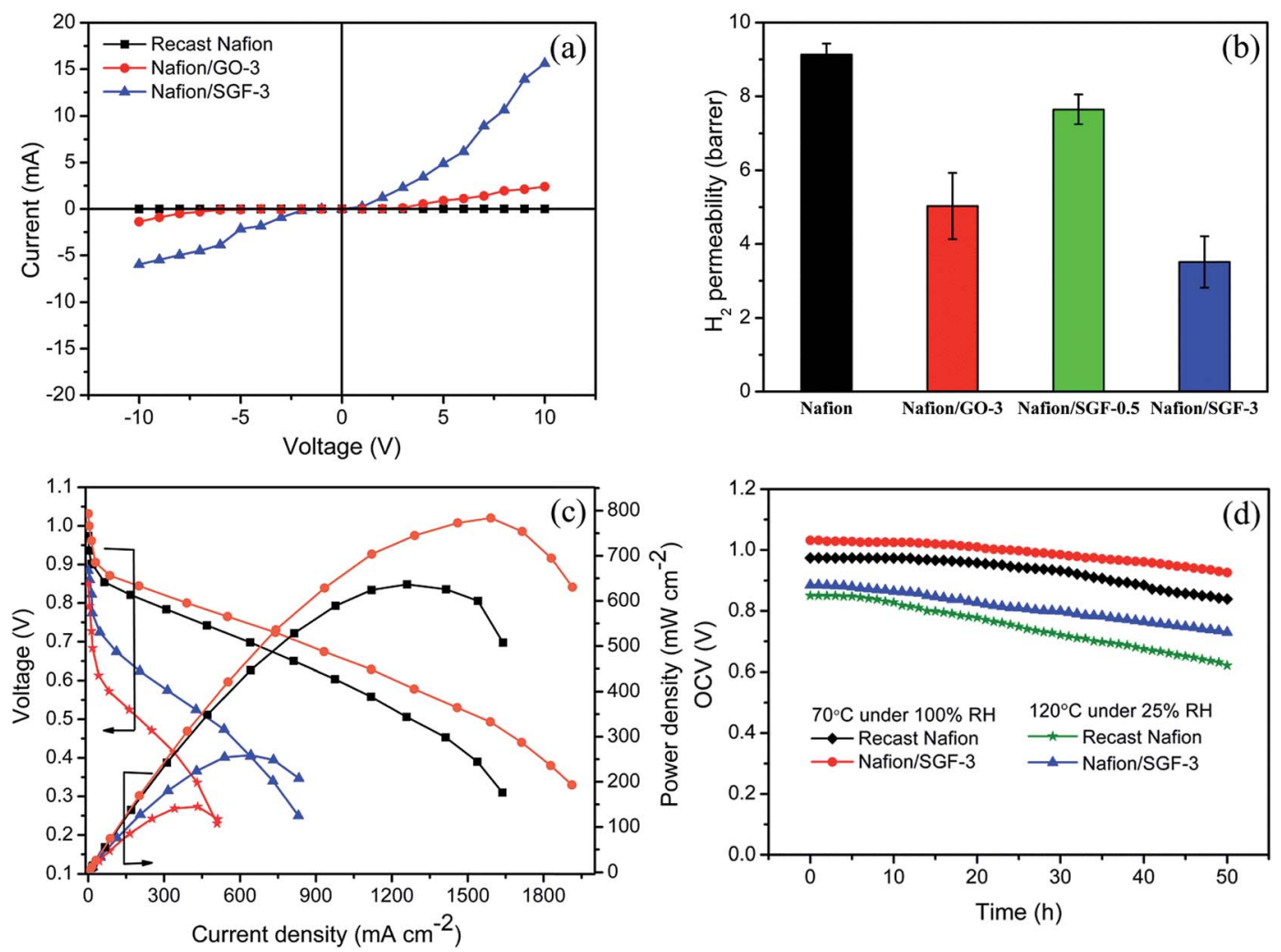

Fig. 8 (a) Current-voltage ( $i-v)$ characteristics of pristine recast Nafion and composite membranes; (b) $\mathrm{H}_{2}$ permeability of pristine recast Nafion and composite membranes; (c) performances of $\mathrm{H}_{2} / \mathrm{O}_{2}$ PEMFC at $70{ }^{\circ} \mathrm{C}$ under $100 \% \mathrm{RH}$ with (घ) pristine recast Nafion and (•) Nafion/SGF-3 and at $120{ }^{\circ} \mathrm{C}$ under $25 \% \mathrm{RH}$ with ( $\star$ ) pristine recast Nafion and ( $\left.\mathbf{\Delta}\right)$ Nafion/SGF-3; (d) stability test of pristine recast Nafion and Nafion/SGF-3 membrane in fuel cell configuration both at $70{ }^{\circ} \mathrm{C}$ under $100 \% \mathrm{RH}$ and $120{ }^{\circ} \mathrm{C}$ under $25 \% \mathrm{RH}$.

the Nafion/SGF-3 membrane hold a greater amount of water due to the presence of $\mathrm{Fe}_{3} \mathrm{O}_{4}-\mathrm{SGO}$, which keep the membrane sufficiently wet under low humidity and enable the corresponding PEMFC to sustain without losing the performance excessively. Table S1 (ESI $\dagger$ ) summarized the various Nafion based membrane performance results reported in literatures, for comparison with present study. ${ }^{\mathbf{1 , 4 , 1 7 , 5 6 - 6 6}}$

Accordingly, the present study provides a novel Nafion composite membrane with $\mathrm{Fe}_{3} \mathrm{O}_{4}$-SGO filler particles which helps to improve proton conductivity and reduce $\mathrm{H}_{2}$ gas crossover. However, $\mathrm{O}_{2}$ gas crossover from the cathode to the anode through PEM is a crucial drawback that leads to generation of $\mathrm{H}_{2} \mathrm{O}_{2}$ and consequently membrane degradation. For the determination of $\mathrm{O}_{2}$ gas crossover of prepared membranes, OCV of the studied membranes-equipped PEMFC was examined for $50 \mathrm{~h}$ at $70{ }^{\circ} \mathrm{C}$ under $100 \% \mathrm{RH}$ (Fig. $8 \mathrm{~d}$ ). After $50 \mathrm{~h}$ of operation, the OCV of the pristine Nafion and Nafion/SGF-3 membrane were found to decrease from 0.97 to $0.83 \mathrm{~V}$ and 1.03 to $0.92 \mathrm{~V}$, respectively. The lower OCV reduction rate of composite membrane indicates its good barrier property against $\mathrm{O}_{2}$ gas diffusion from the cathode to anode, which can be attributed to the presence of $\mathrm{Fe}_{3} \mathrm{O}_{4}$-SGO. To address effect of high temperature operation, OCV of the membranes-equipped PEMFC was examined at $120{ }^{\circ} \mathrm{C}$ under $25 \% \mathrm{RH}$. By comparison, the accelerated OCV degradations are observed for both pristine Nafion and Nafion/SGF-3 membranes, which represent the rapid chemical degradation of membranes during high temperature operation.

\section{Conclusion}

Nafion composite membranes, incorporating different wt\% of $\mathrm{Fe}_{3} \mathrm{O}_{4}$-SGO, were successfully fabricated via a facile solution casting method. In the composite membranes, the number of $-\mathrm{SO}_{3} \mathrm{H}$ groups per cluster volume domain was increased by SGO, and the hydrogen bonding networks between $-\mathrm{SO}_{3} \mathrm{H}$ groups were extended by $\mathrm{Fe}_{3} \mathrm{O}_{4}$. Because of the high density of $-\mathrm{SO}_{3} \mathrm{H},-\mathrm{CO}_{2} \mathrm{H}$ and $-\mathrm{OH}$ groups on $\mathrm{Fe}_{3} \mathrm{O}_{4}-\mathrm{SGO}$, the water uptake, ion exchange capacity and proton conductivity of the composite membrane significantly increased. The incorporation of $\mathrm{Fe}_{3} \mathrm{O}_{4}-\mathrm{GO}$ restructured the aliphatic chains of Nafion through hydrogen bonding, which strengthened the membrane mechanically and thermally by 3.16 and 31.6 fold, respectively. By the combined efforts of high surface area and strong-acid functionalities of $\mathrm{Fe}_{3} \mathrm{O}_{4}-\mathrm{GO}$, composite membrane harvested number of protons and ameliorates the PEMFC performance at high temperature and low humidity condition compared to the PEMFC containing pristine Nafion membrane.

\section{Conflicts of interest}

The all authors declare that they have no conflict of interest. 


\section{Acknowledgements}

This work was supported by the Korea Institute of Energy Technology Evaluation and Planning (KETEP) and the Ministry of Trade, Industry \& Energy (MOTIE) of the Republic of Korea (No. 20164030201070). This research was supported by Basic Science Research Program through the National Research Foundation of Korea (NRF) funded by the Ministry of Science, ICT and Future Planning (NRF-2017R1A2B4005230).

\section{References}

1 H. Zarrin, D. Higgins, Y. Jun, Z. Chen and M. Fowler, J. Phys. Chem. C, 2011, 115, 20774-20781.

2 M. Vinothkannan, A. R. Kim, G. Gnanakumar, J. M. Yoon and D. J. Yoo, RSC Adv., 2017, 7, 39034-39048.

3 K. D. Papadimitriou, F. Paloukis, S. G. Neophytides and J. K. Kallitsis, Macromolecules, 2011, 44, 4942-4951.

4 K. Ketpang, K. Lee and S. Shanmugam, ACS Appl. Mater. Interfaces, 2014, 6, 16734-16744.

5 A. M. Baker, L. Wang, W. B. Johnson, A. K. Prasad and S. G. Advani, J. Phys. Chem. C, 2014, 118, 26796-27802.

6 S. Neelakandan, N. K. Jacob, P. Kanagaraj, R. M. Sabarathinam, A. Muthumeenal and A. Nagendran, RSC Adv., 2016, 6, 51599-51608.

7 S. Zhou, S. D. Hai and D. Kim, Fuel Cells, 2012, 12, 589598.

8 S. G. Peera, S. Meenakshi, K. H. Gopi, S. D. Bhat, P. Sridhar and S. Pitchumani, RSC Adv., 2013, 3, 14048-14056.

9 H. Beydaghi, M. Javanbakht, A. Bagheri, P. Salarizadeh, H. G. Zahmatkesh, S. Kashefi and E. Kowsari, RSC Adv., 2015, 5, 74054-74064.

10 V. Parthiban, S. Akula, S. G. Peera, N. Islam and A. K. Sahu, Energy Fuels, 2016, 30, 725-734.

11 H. Zhang, T. Zhang, J. Wang, F. Pei, Y. He and J. Liu, Fuel Cells, 2013, 13, 1155-1165.

12 V. Tricoli and F. Nannetti, Electrochim. Acta, 2003, 48, 26252633.

13 E. Chalkova, C. Wang, S. Komarneni, J. K. Lee, M. V. Fedkin and S. N. Lvov, ECS Trans., 2009, 25, 1141-1150.

14 P. Kalappa and J. H. Lee, Polym. Int., 2007, 56, 371375.

15 Q. Yang, J. Liu, J. Yang, M. P. Kapoor, S. Inagaki and C. Li, J. Catal., 2004, 228, 265-272.

16 A. R. Kim, M. Vinothkannan and D. J. Yoo, Composites, Part B, 2017, 130, 103-118.

17 A. K. Sahu, K. Ketpang, S. Shanmugam, O. Kwon, S. Lee and H. Kim, J. Phys. Chem. C, 2016, 120, 15855-15866.

18 G. Rambabu, N. Nagaraju and S. D. Bhat, Chem. Eng. J., 2016, 306, 43-52.

19 Y. L. Liu, Y. H. Su, C. M. Chang, Suryani, D. M. Wang and J. Y. Lai, J. Mater. Chem., 2010, 20, 4409-4416.

20 A. K. Geim, Science, 2009, 324, 1530-1534.

21 F. Schedin, A. K. Geim, S. V. Morozov, E. W. Hill, P. Blake, M. I. Katsnelson and K. S. Novoselov, Nat. Mater., 2007, 6, 652-655.
22 H. Zhang, X. Lv, Y. Li, Y. Wang and J. Li, ACS Nano, 2010, 4, 380-386.

23 W. Chen, L. Duan, L. Wang and D. Zhu, Environ. Sci. Technol., 2008, 42, 6862-6868.

24 D. H. Kim, J. H. Ahn, W. M. Choi, H. S. Kim, T. H. Kim, J. Song, Y. Y. Huang, Z. Liu, C. Lu and J. A. Rogers, Science, 2008, 320, 507-511.

25 G. Eda, G. Fanchini and M. Chhowalla, Nat. Nanotechnol., 2008, 3, 270-274.

26 X. Wang, L. Zhi and K. Mullen, Nano Lett., 2008, 8, 323-326.

27 E. Yoo, J. Kim, E. Hosono, H. S. Zhou, T. Kudo and I. Honma, Nano Lett., 2008, 8, 2277-2282.

28 M. Vinothkannan, A. R. Kim, K. S. Nahm and D. J. Yoo, $R S C$ Adv., 2016, 6, 108851-108863.

29 M. R. Karim, K. Hatakeyama, T. Matsui, H. Takehira, T. Taniguchi, M. Koinuma, Y. Matsumoto, T. Akutagawa, T. Nakamura, S. Noro, T. Yamada, H. Kitagawa and S. Hayami, J. Am. Chem. Soc., 2013, 135, 8097-8100.

30 H. Beydaghi, M. Javanbakht and E. Kowsari, Ind. Eng. Chem. Res., 2014, 53, 16621-16632.

31 G. Gnana kumar, C. J. Kirubaharan, D. J. Yoo and A. R. Kim, Int. J. Hydrogen Energy, 2016, 41, 13208-13219.

32 J. Salamon, Y. Sathishkumar, K. Ramachandran, Y. S. Lee, D. J. Yoo, A. R. Kim and G. G. Kumar, Biosens. Bioelectron., 2015, 64, 269-276.

33 H. Beydaghi and M. Javanbakht, Ind. Eng. Chem. Res., 2015, 54, 7028-7037.

34 W. S. Hummers and R. E. Offeman, J. Am. Chem. Soc., 1958, 80, 1339.

35 K. H. Lee, J. Y. Chu, A. R. Kim, K. S. Nahm, C. J. Kim and D. J. Yoo, J. Membr. Sci., 2013, 434, 35-43.

36 S. Gahlot and V. Kulshrestha, ACS Appl. Mater. Interfaces, 2015, 7, 264-272.

37 L. Zhao, Y. Li, H. Zhang, W. Wu, J. Liu and J. Wang, J. Power Sources, 2015, 286, 445-457.

38 A. R. Kim, M. Vinothkannan and D. J. Yoo, Int. J. Hydrogen Energy, 2017, 42, 4349-4365.

39 A. Ghosh, S. Basu and A. Verma, Fuel Cells, 2013, 13, 355363.

40 S. Gahlot, P. P. Sharma, V. Kulshrestha and P. K. Jha, ACS Appl. Mater. Interfaces, 2014, 6, 5595-5601.

41 J. Liu, D. Takeshi, K. Sasaki and S. M. Lyth, Fuel Cells, 2014, 14, 728-734.

42 M. Vinothkannan, C. Karthikeyan, G. Gnana kumar, A. R. Kim and D. J. Yoo, Spectrochim. Acta, Part A, 2015, 136, 256-264.

43 N. Jiang, Z. Xiu, Z. Xie, H. Li, G. Zhao, W. Wang, Y. Wu and X. Hao, New J. Chem., 2014, 38, 4312-4320.

$44 \mathrm{X}$. Liu, N. Wen, X. Wang and Y. Zheng, Nanomater. Nanotechnol., 2015, 5, 14-20.

45 X. Li, J. Feng, Y. Du, J. Bai, H. Fan, H. Zhang, Y. Peng and F. Li, J. Mater. Chem. A, 2015, 3, 5535-5546.

46 B. Dehghanzad, M. K. R. Aghjeh, O. Rafeie, A. Tavakoli and A. J. Oskooie, $R S C A d v$. , 2016, 6, 3578-3585.

47 A. Muthumeenal, S. Neelakandan, D. Rana, T. Matsuura, P. Kanagaraj and A. Nagendran, Fuel Cells, 2014, 14, 853861. 
48 S. P. Tung and B. J. Hwang, Fuel Cells, 2007, 7, 32-39.

49 S. Gahlot, H. Gupta, P. K. Jha and V. Kulshrestha, ACS Omega, 2017, 2, 5831-5839.

50 X. H. He, Y. Zheng, H. L. Yao, Y. W. Chen and D. F. Chen, Fuel Cells, 2014, 14, 26-34.

51 A. Bagheri, M. Javanbakht, H. Beydaghi, P. Salarizadeh, A. Shabanikia and H. S. Amoli, RSC Adv., 2016, 6, 3950039510.

52 Z. Jiang, X. Zhao, Y. Fu and A. Manthiram, J. Mater. Chem., 2012, 22, 24862-24869.

53 K. Oh, B. Son, J. Sanetuntikul and S. Shanmugam, J. Membr. Sci., 2017, 541, 386-392.

54 Y. Jin, S. Qiao, J. C. D. Costa, B. J. Wood, B. P. Ladewig and G. Q. Lu, Adv. Funct. Mater., 2007, 17, 3304-3311.

55 K. D. Kreuer, Chem. Mater., 1996, 8, 610-641.

56 K. Feng, B. Tang and P. Wu, ACS Appl. Mater. Interfaces, 2013, 5, 1481-1488.

57 X. He, G. He, A. Zhao, F. Wang, X. Mao, Y. Yin, L. Cao, B. Zhang, H. Wu and Z. Jiang, ACS Appl. Mater. Interfaces, 2017, 9, 27676-27687.
58 A. K. Mishra, N. H. Kim, D. Jung and J. H. Lee, J. Membr. Sci., 2014, 458, 128-135.

59 R. Kumar, C. Xu and K. Scott, RSC Adv., 2012, 2, 8777-8782. 60 D. C. Lee, H. N. Yang, S. H. Park, K. W. Park and W. J. Kim, J. Membr. Sci., 2015, 474, 254-262.

61 S. Sasikala, S. V. Selvaganesh, A. K. Sahu, A. Carbone and E. Passalacqua, J. Membr. Sci., 2016, 499, 503-514.

62 K. Ketpang, B. Son, D. Lee and S. Shanmugam, J. Membr. Sci., 2015, 488, 154-165.

63 W. Zhengbang, T. Haolin and P. Mu, J. Membr. Sci., 2011, 369, 250-257.

64 V. Ramani, H. R. Kunz and J. M. Fenton, J. Membr. Sci., 2004, 232, 31-44.

65 Y. Kim, K. Ketpang, S. Jaritphun, J. S. Park and S. Shanmugam, J. Mater. Chem., 2015, 3, 8148-8155.

66 K. Ketpang, S. Shanmugam, C. Suwanboon, N. Chanunpanich and D. Lee, J. Membr. Sci., 2015, 493, 285-298. 